\title{
ORGANIZATIONAL CHALLENGES FACING SCHOOL ADMINISTRATORS IN TULKAREM DIRECTORATE FROM THE POINT OF VIEW OF THE SCHOOL PRINCIPALS THEMSELVES
}

http://dx.doi.org/10.47832/2757-5403.4-3.5

\section{Mahmoud Jameel Mahmoud HOSSIN ${ }^{1}$}

\begin{abstract}
:
The study aims to identify the organizational challenges facing school administrators in Tulkarem directorate from the point of view of the school principals themselves. In addition, it shows the impact of the variables related to the gender, qualification, experience and geographical location on organizational challenges.

An online questionnaire was used as a tool to collect data. The study sample consisted of 138 male and female principals selected randomly. Moreover, the descriptive analytical approach was used to analyze the data through the SPSS statistical analysis software, and to draw the conclusions.

The results of the research have shown that the section stating the principals' lack of familiarity with new developments in management science and the lack of valid basic data needed to prepare plans was great. In addition, the arithmetic average was very big for the sections stating the following: the proliferation of generalizations and decisions in such a way which makes following up their implementation take time and effort at the expense of other work, obligating schools to follow rules and instructions to the letter, poor cooperation between the school administration and senior levels of administration, and the regulations established on ideal grounds are difficult to be realistically complied with at schools. Moreover, the results have indicated that there were no individual differences in the most common organizational administrative challenges among public school principals in Tulkarem governorate according to gender, specialization, qualification and years of experience.

The researcher recommends that schools should be provided with integral administrative staff, schools should be also provided with equipment and materials, principals should be given more authority especially with regard to students' problems, teachers should be
\end{abstract}

\footnotetext{
${ }^{1}$ Researcher, Arab American University, Palestine, mgmh2019hw@gmail.com, https://orcid.org/0000-0001$\underline{9800-8462}$
}

Copyright (C) Published by IJHER Journal, www.ijherjournal.com Rimar Academy, Fatih, Istanbul, 34093 Turkey

All rights reserved 


\title{
ORGANIZATIONAL CHALLENGES FACING SCHOOL ADMINISTRATORS IN TULKAREM DIRECTORATE FROM THE POINT OF VIEW OF THE SCHOOL PRINCIPALS THEMSELVES
}

provided and their teaching loads should be reduced, accurate scientific criteria should be established for selecting and training members of school administration, overlapping of school administration specialties should be avoided, and communication channels should be established between the school administration and educational administration.

Key words: Organizational Challenges, Organizational Structure, Governmental Schools, Tulkarm District.

\section{المشكلات التظيمية التي تواجه الإدارة المدرسية في مديرية طولكرم شمال فلسطين من من فيرئ وجهة نظر مديري ومديرات المدارة المدرسية في مديرسة طنفهرم \\ 2 \\ محمود جميل محمود حسين}

\begin{abstract}
الملخص
هدفت الدراسة التعرف إلى المشكلات التنظيمية التي تواجه الإدارة المدرسية في مديرية

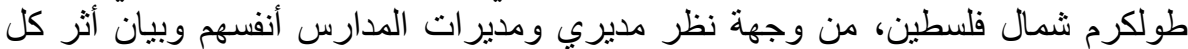

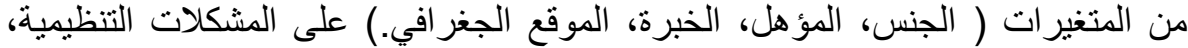

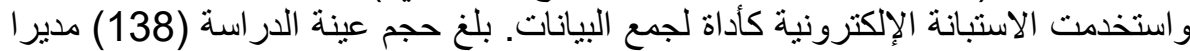

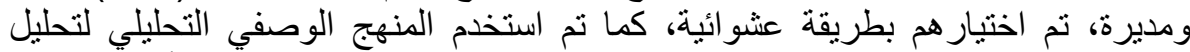

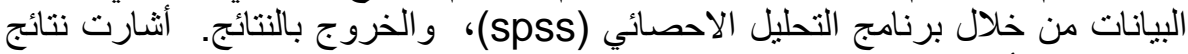

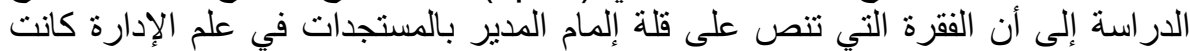

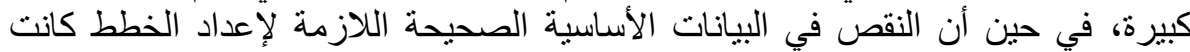

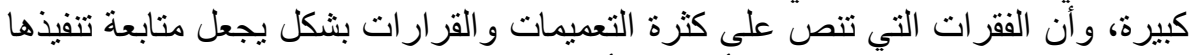

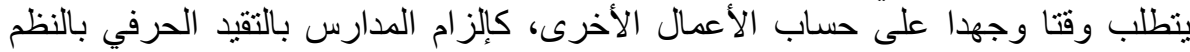

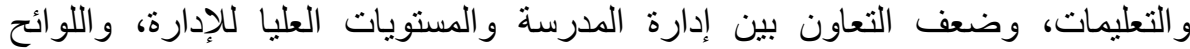

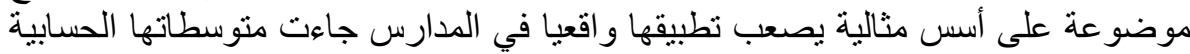

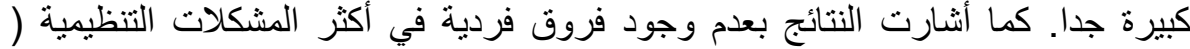

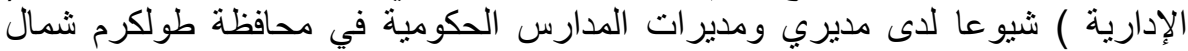

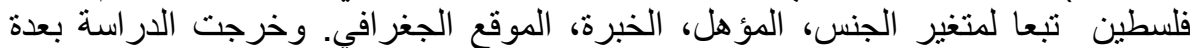

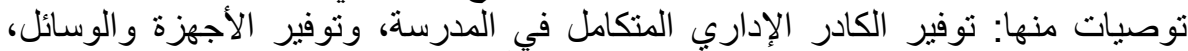

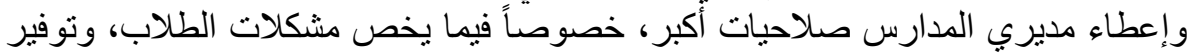

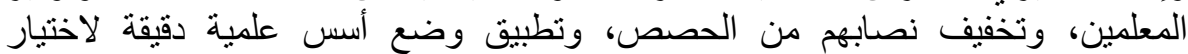

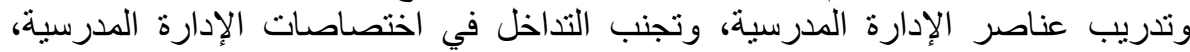

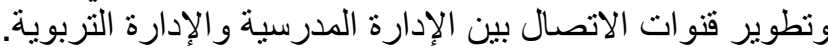
الكلمات المفتاحية: المشكلات التنظيمية، الهيكل التنظيمي، المدارس التئنة الحكومية قضاء طولكرم فلسطين، الادارة المدرسية.
\end{abstract}

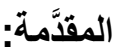

يشهد العالم الآن ثُرة هائلة في تكنولوجيا المعلومات، والتقدم العلمي، بحيث أصبح التنافس بين القوى في العالم يرتكز

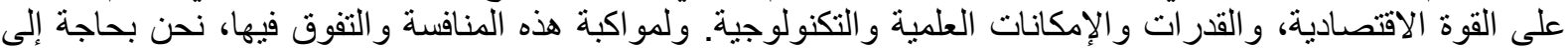

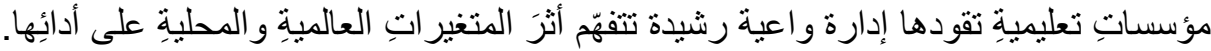

mgmh2019hw@gmail.com الباحث، الجامعة العربية الأمريكية ، فلسطين، 
وترتبط الإدارة المدرسية بالعملية التعليمية، وهى من أهم عناصر الميدان التربوي التي تخضع دائماً للار اسة والتمحيص،

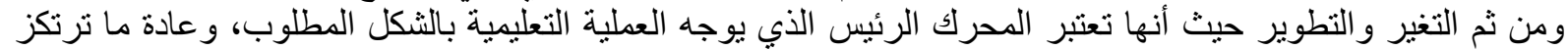

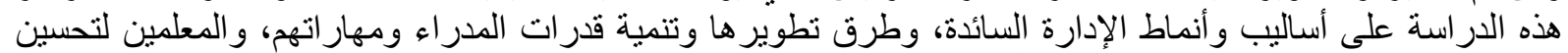

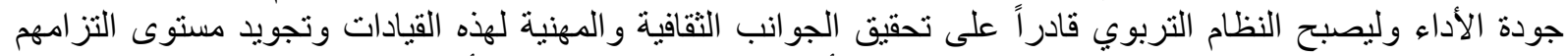

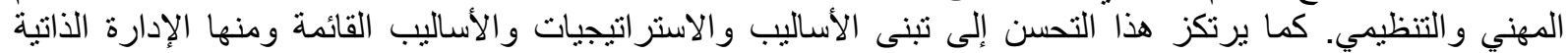

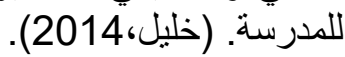

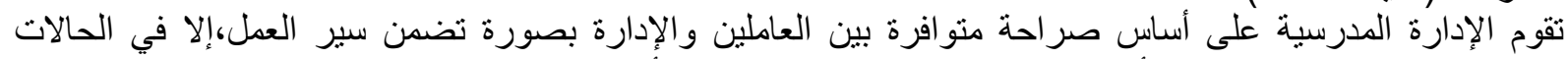

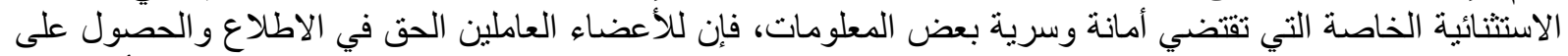

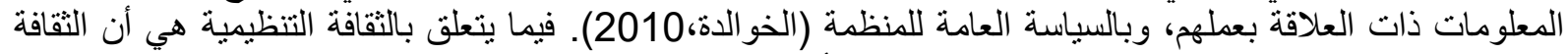

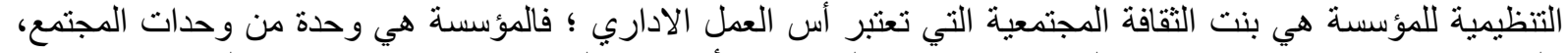

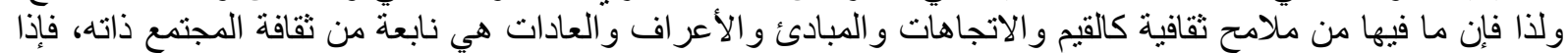
كان الحرص على ملى جودة الأداء ملحوظاً كملمح من ملامح ثقافتها التنظيمية، فان معنى معنى ذللك أن المجتمع الكبير يتميز بأنه

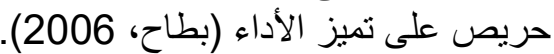

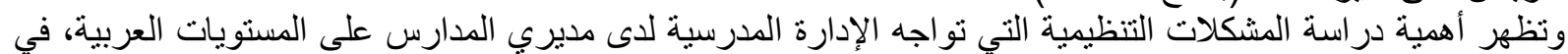

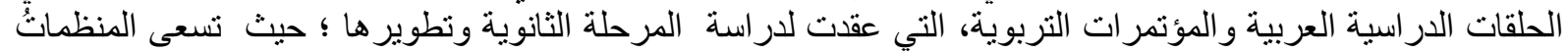

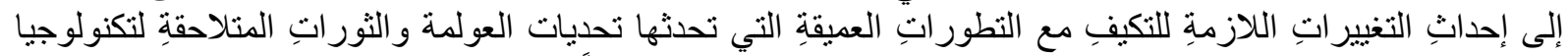

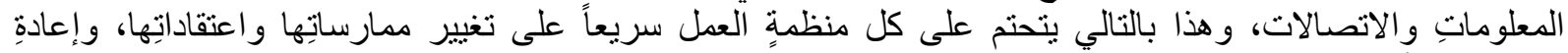

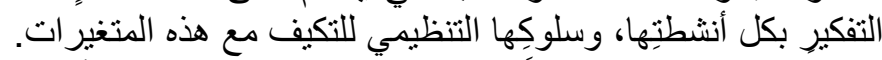

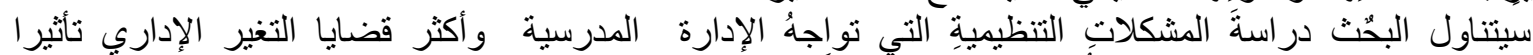

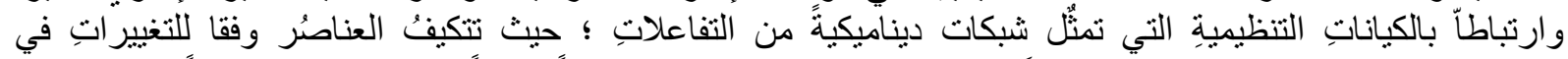

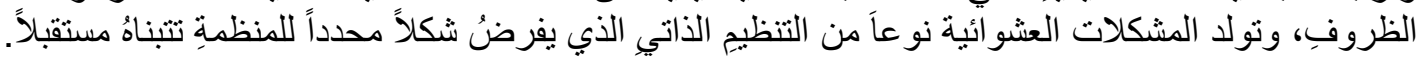

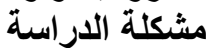

لاحظ الباحثان من خلالِ اطلاعهما على الأدب النظريّ و الدراساتِ السابقة، أن تحديد المشكلات التنظيمية ( الإدارية )،

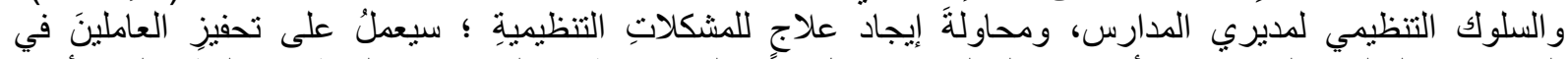

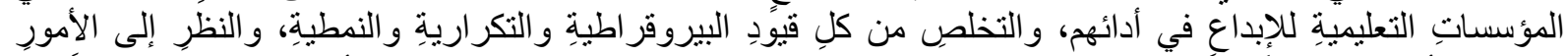

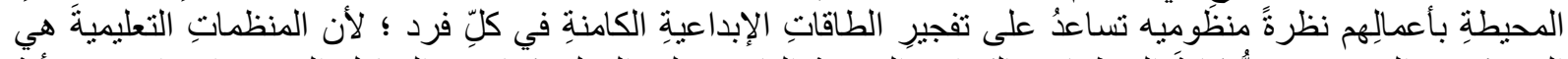

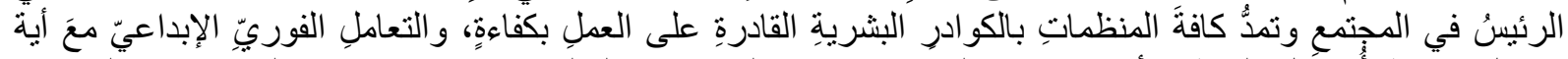

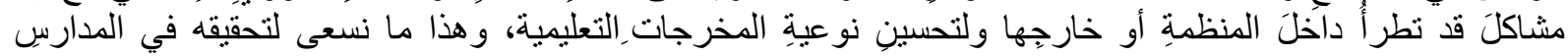

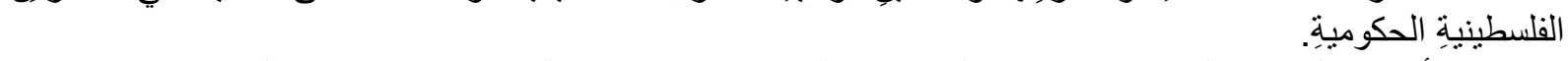
ومن هنا يأتي منطلق هذه الدراسة في تحديد المشكلات التنظيمية ( الإدارية) التي تواجهها الإدارة المدرسية في مدارس

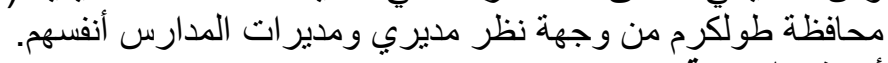

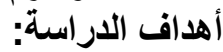

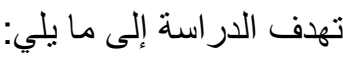
• التعرف على أكثر المشكلات التنظيمية ( الإدارية ) شيو عا لدى مديري ومديرات المدارس الحكومية في محافظة

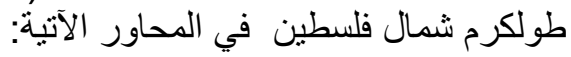

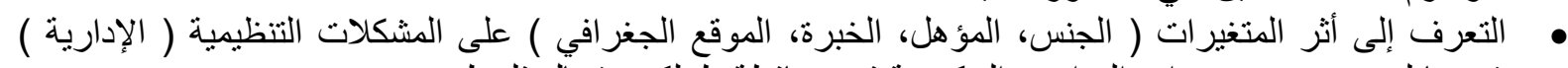

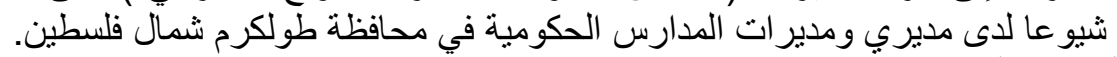

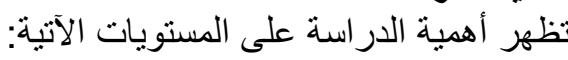

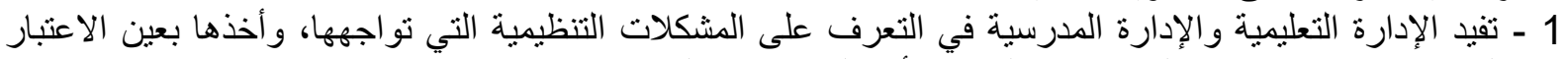

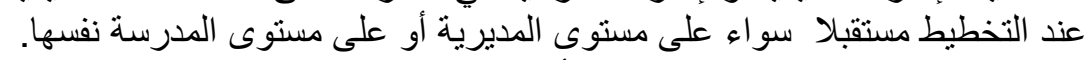

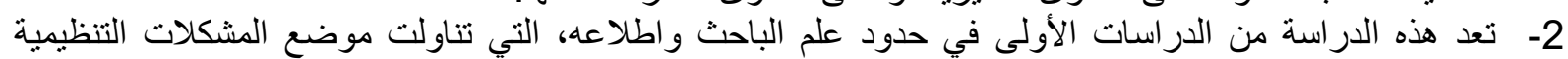

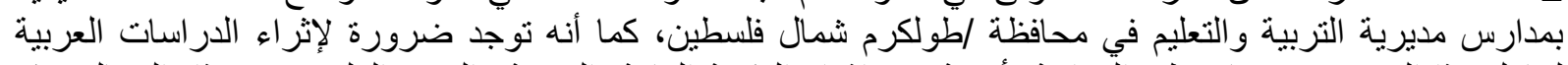

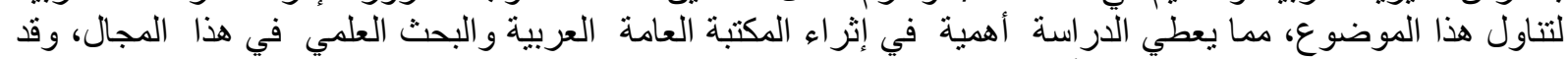

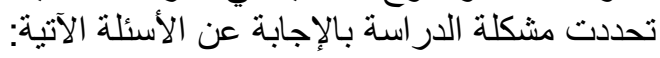

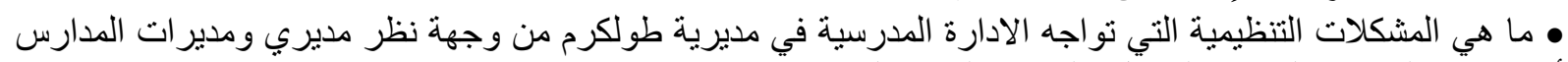

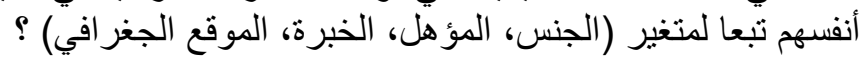




\section{ORGANIZATIONAL CHALLENGES FACING SCHOOL ADMINISTRATORS IN TULKAREM DIRECTORATE FROM THE POINT OF VIEW OF THE SCHOOL PRINCIPALS THEMSELVES}

التساؤلات الفرعية الأخرى: • ما هي المشكلات التنظيمية التي تواجه الإدارة المدرسية في مديرية طولكرم شمال فلسطين من وجهة نظر مديري

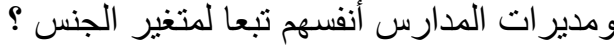
• ما هي المشكلات التنظيمية التي تواجه الإدارة المدرسية في مديرية طولكرم شمال فلسطين من وجهة نظر مديري ومديرات المدارس أنفسهم تبعا لمتغير المؤهل هل التها

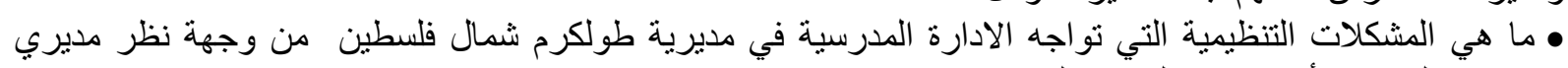

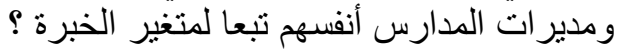
• ما هي المشكلات التنظيمية التي نواجها التهائ الادارة المدرسية في مديرية طولكرم شمال فلسطين من وجهة نظر مديري

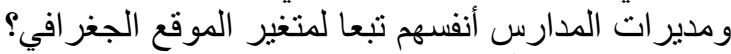

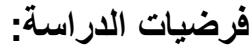
1. لا نوجد فروق ذات دلالة إحصائية عند مستوى دلالة ( a=0.05)، من حيث المشكلات التنظيمية في المدارس

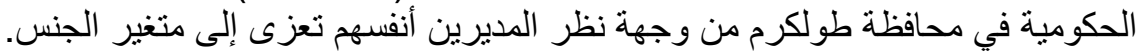

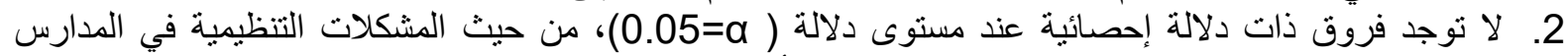

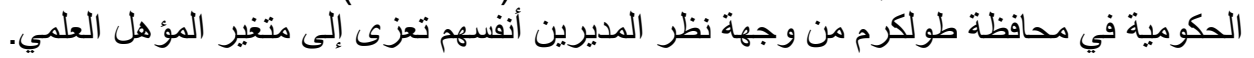

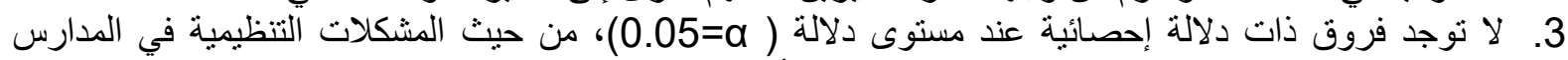

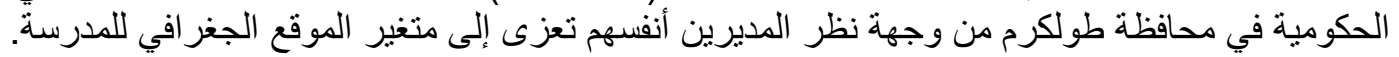

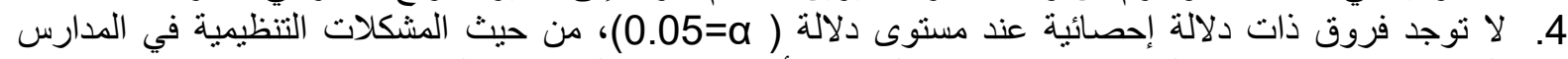
الحكومية في محافظة طولكرم من وجهة نظر المديرين أنفسهم تعزى إلى إلى متغير الخبرة الإدارية.

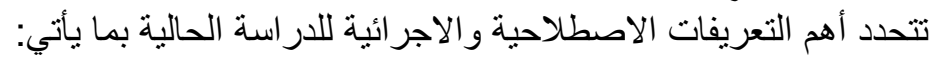
الهيكل التنظيمي بالمدرسة: هو الإطار التنظيمي الذي يتكون من بطاقات نوصيف بليف الوظائف، والخريطة التنظيمية،

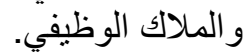

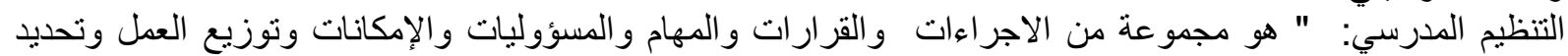

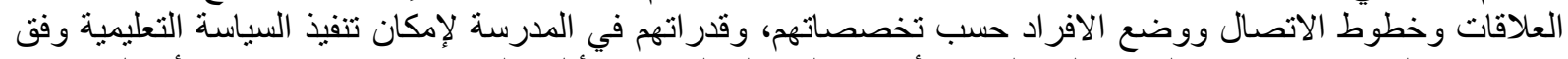

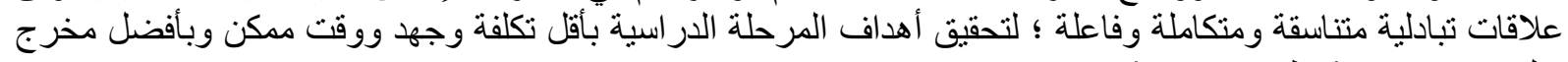
تعليمي تربوي ".(عطوي، البانية ويعرفت الباحث المناخ ألتنظيمي إجرائيا: على أنه محصلة التفاعل بين التشريعات الخاصة للعملية التعليمية في واقعها

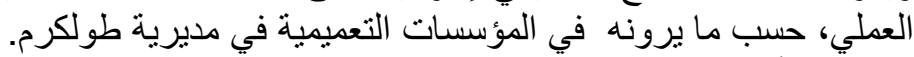

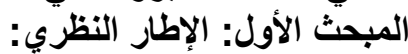

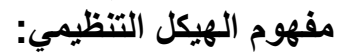

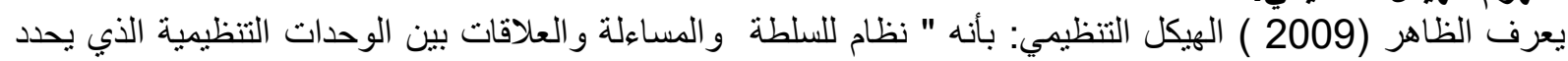
شكل وطبيعة العمل اللازم للمنظمة، وهو الإطار الذي تمارس الإدارة بداخله وظائفيا ".

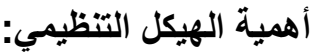
يؤدي الهيكل التنظيمي دوراً حيوياً في إدر الك المؤسسة وبلو غها غاياتها، و أهدافها بكفاءة وفاعلية،

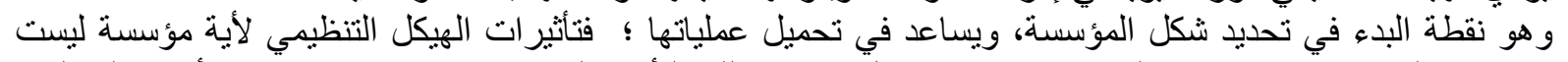

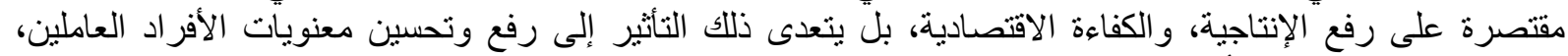
وتحقيق الرضا، وتفعيل الأداء التنظيمي (الظاهر ، الأنغاءة 2009).

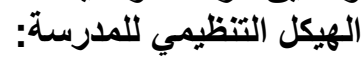

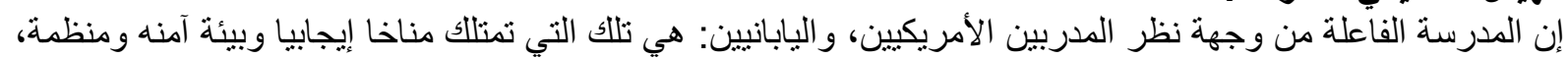

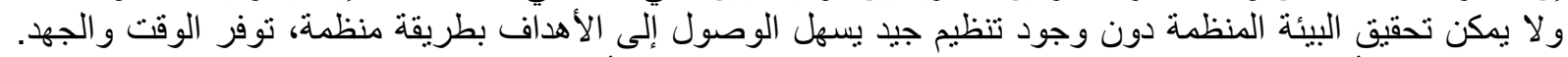

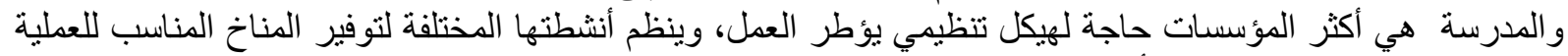

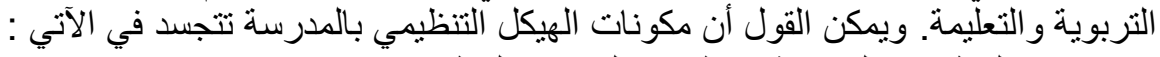
ـ ـ توصيف الوظائف بالمدرسة " بطاقات الوصف الونف الوظيفي ". ـ ـ الملاك الوظيفي بالمدرسة. ـ الجدول المدرسي. 
- 2 - 2ليل إجر اءات العمل بالمدرسة. ـ - تقارير تقييم الأداء العاملين. - ل الائحة المساءلة و النأديب.

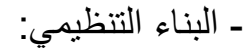

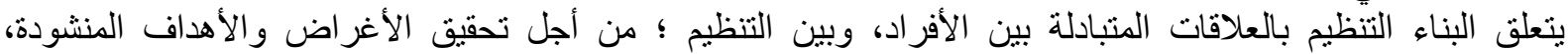
ويتضمن هذا الجانب عناصر رئيسة في مقدمتها المفاهيم المتعلقة بالمنظمة الرسمية وغير الرئية الرسمية، والسلطة و الرقابة الرية

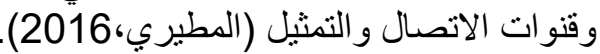

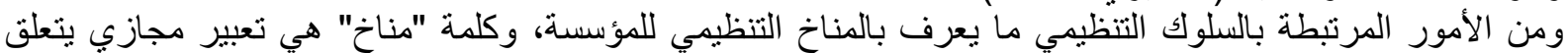

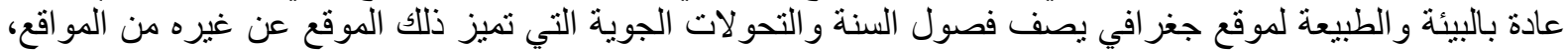

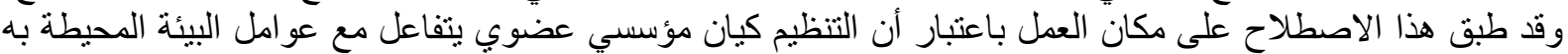

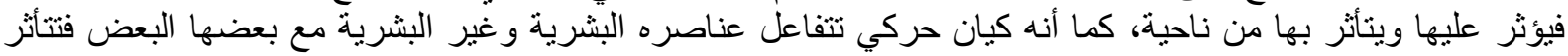

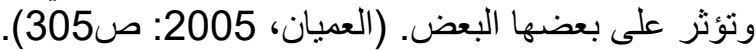

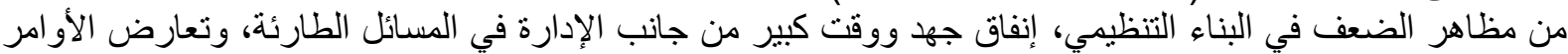

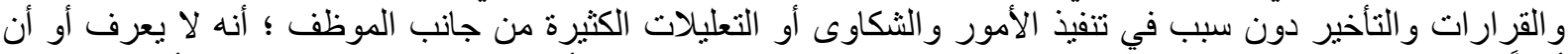

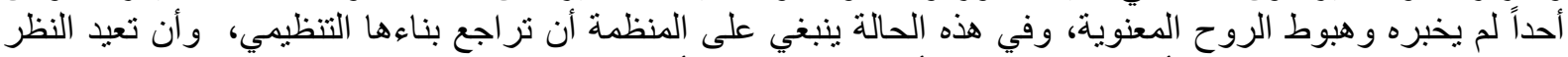

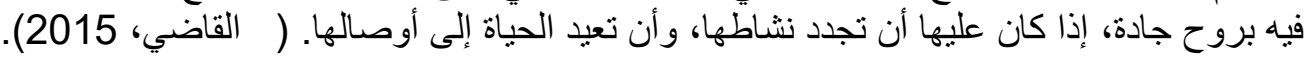

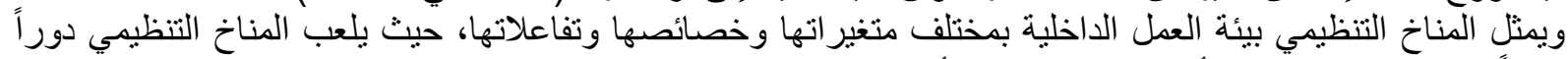

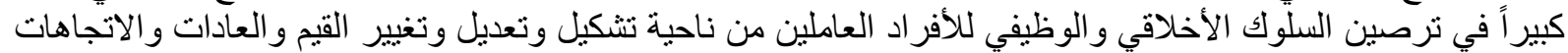

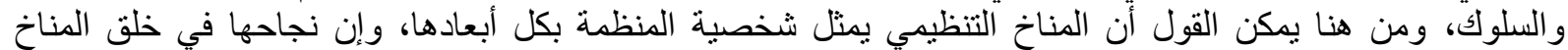

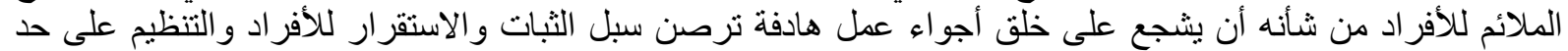

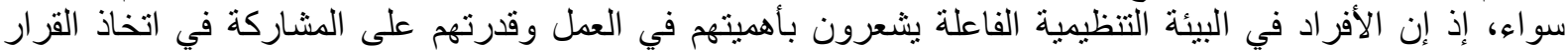

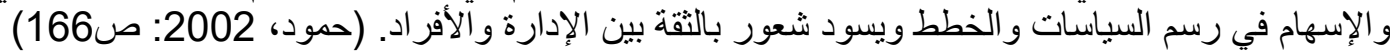

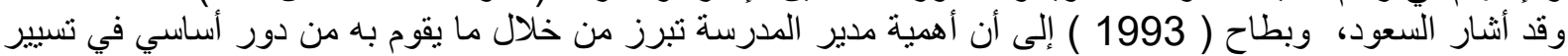

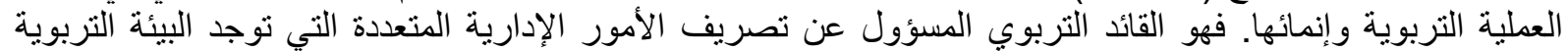

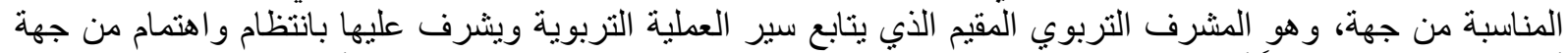

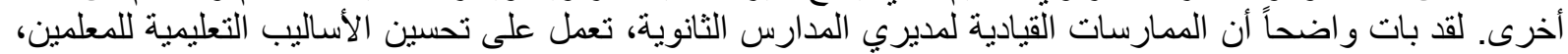

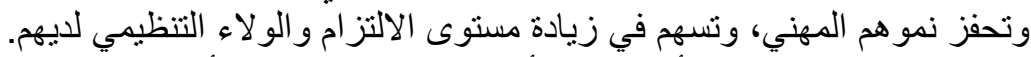

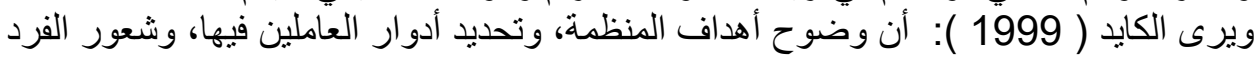

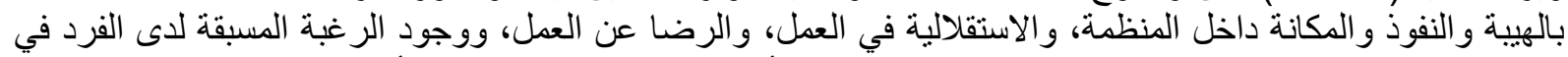

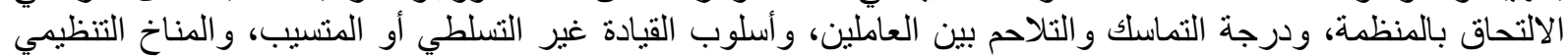

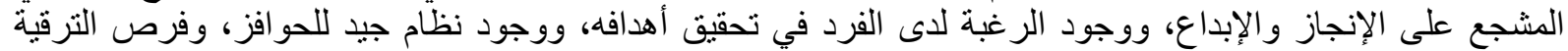

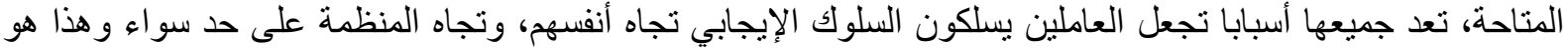
جو هر عملية الولاء التنظيمي.

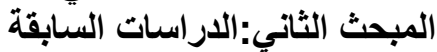

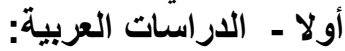

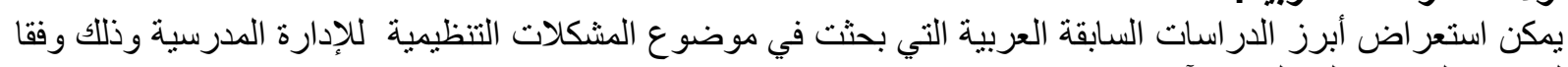
لترنيبها الزمني على النحو النحو الآتي:

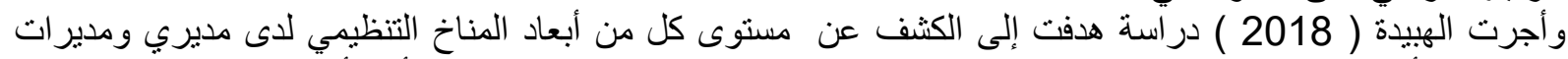

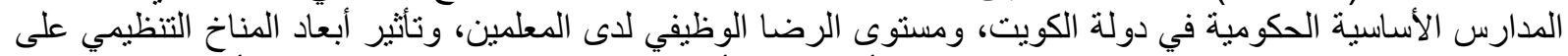

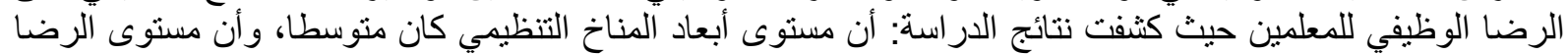

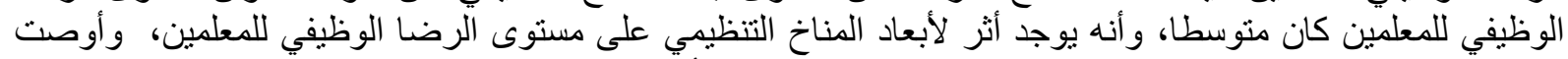

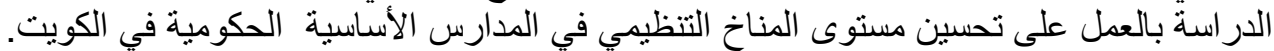

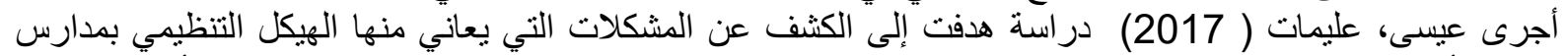

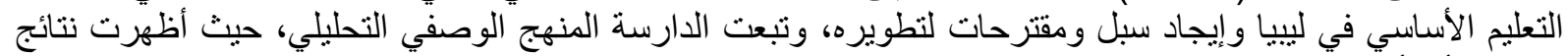

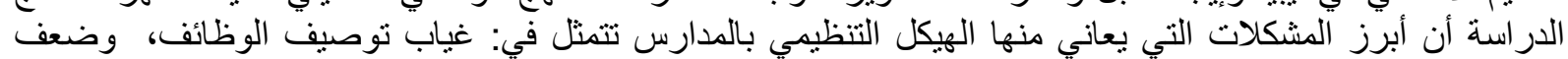

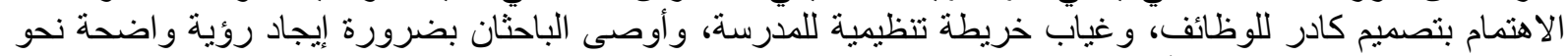

تنظيم وهيكلة مدارس التعليم الأساسي في ليبيا.

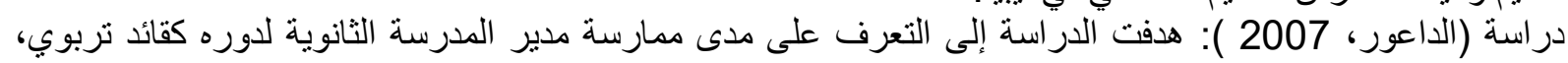
و التعرف علي نمط الثقافة التنظيمية السائد في المدارس الثانوية، ومعرفة العلاقة بين مدى ممارسة مدير المدرسة الثانوية لثرية 


\section{ORGANIZATIONAL CHALLENGES FACING SCHOOL ADMINISTRATORS IN TULKAREM DIRECTORATE FROM THE POINT OF VIEW OF THE SCHOOL PRINCIPALS THEMSELVES}

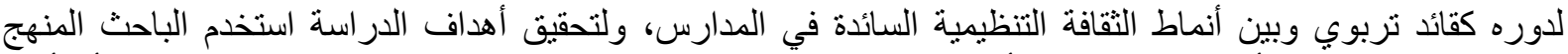

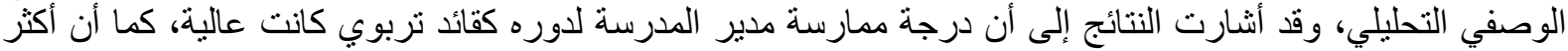

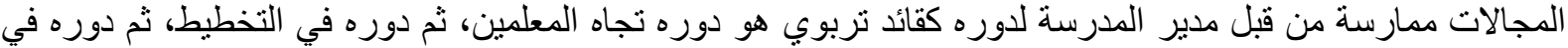

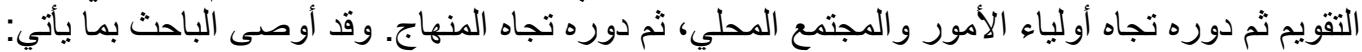

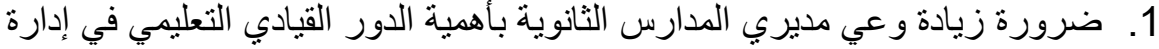
2. المدارس وخاصة في النو احي الفنية. 3. ضرورة اهتمام المديرين بالَعلاقات الإنسانية الطيبة.

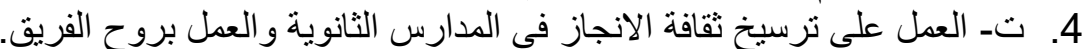
دراسة مقبل ( 2004 م ): هدفت الدراسة إلى التعرف إلى إلى مستوى التي التحسن في في أداء مديري المدارس نتيجة تطبيق

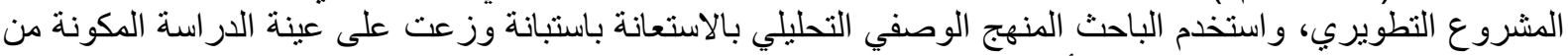

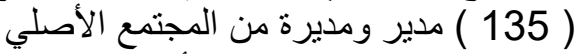

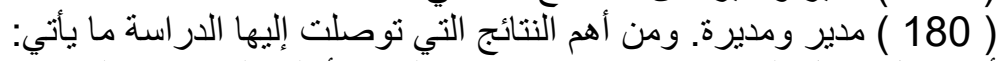

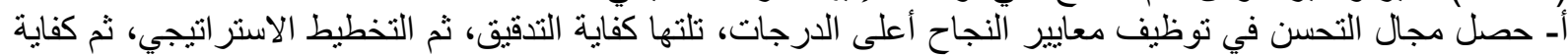

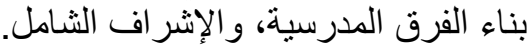
ب-حصل مستوى التحسن في كفاية التعامل مع المجتمع المحلي واء التفاوض على على أقل نسبة.

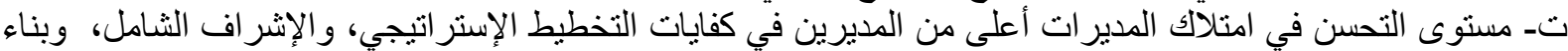

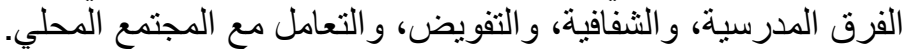

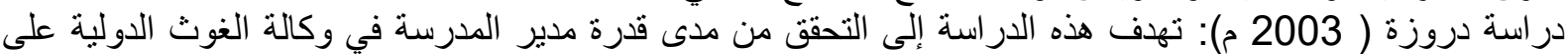

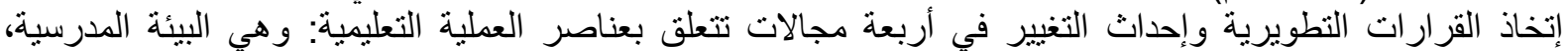

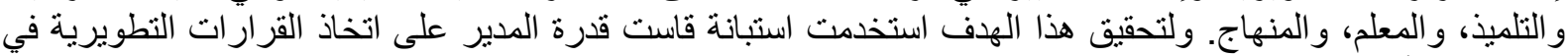
المجالات الأربعة المذكورة، وقد طبقت على عينة عشوائية من مديري مدارس وكالة الغوث الدولية في منطقة نابلس من فلسطين.

بلغت( 26 ) مدير ومديرة من أصل ( 40 ). وقد استخدمت الباحتة الإحصاء الوصفي، وتحليل التباين الأحادي، وتحليل

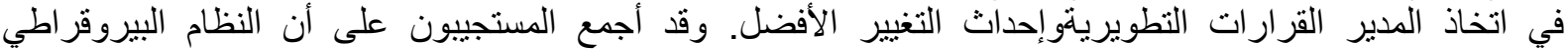

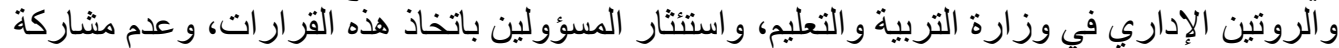

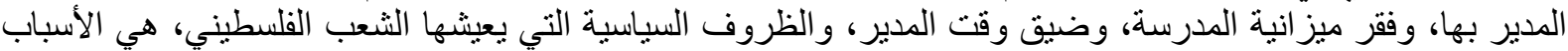

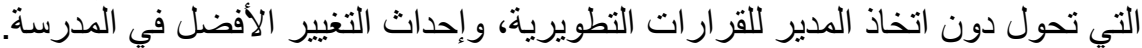

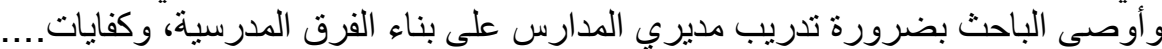

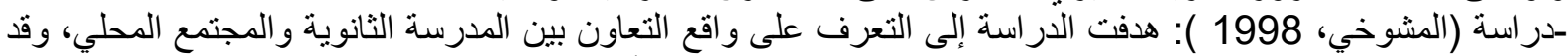

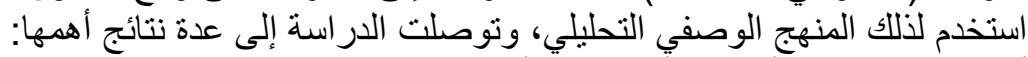

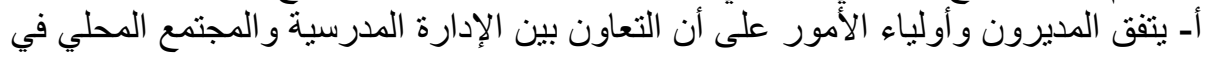
مستوى مندن. ب- أكثر المجالات تعاونًا بين المدرسة والمجتمع المحلي: هو مجال حل مشكلات التلاميذ، ومتابعة مستوى تقدم التلاميذ

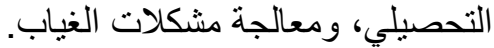

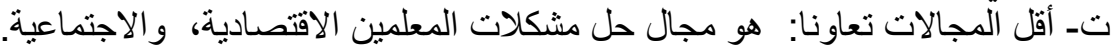

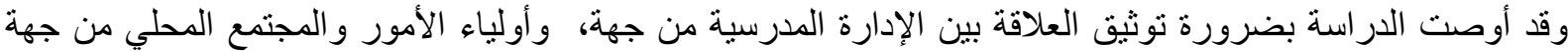

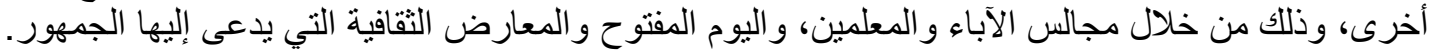

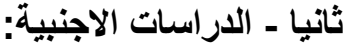
يمكن استعر اض أبرز الدر اسات السابقة الأجنبية التي بحثت في موضوع معوقات الإدارة المدرسية، وذلك وفقا لترتيبها

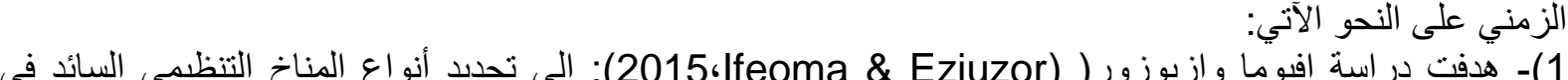

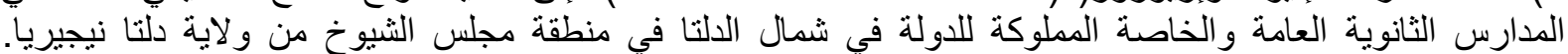

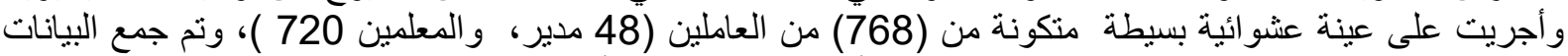

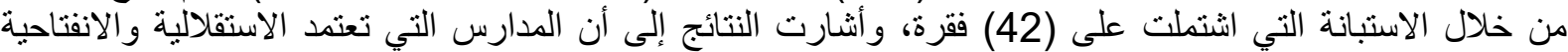
و الرقابة الذاتية تعمل على ايجاد مناخ تنظيمي داعم للموظفين في المدارس المبحوثة. 
2) أما دراسة بوثا جي (Botha.R.J2013): و التي تهدف إلى إصلاح المدرسة في ضوء في قيادة مدرسية إبداعية،

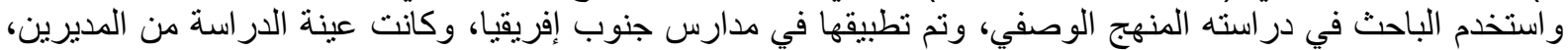

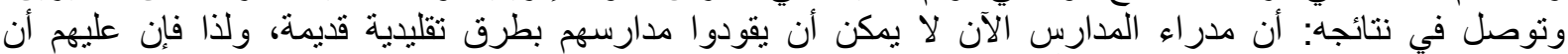

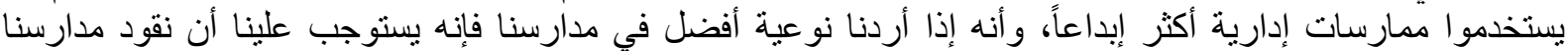

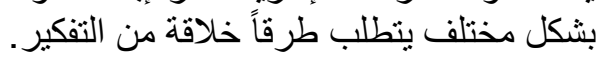
التعليق على الاراسات السابقة:

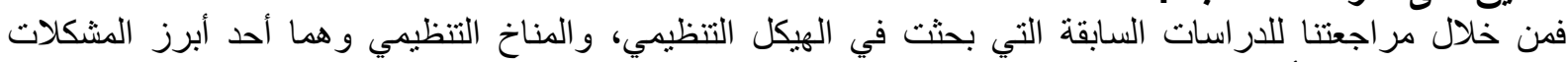

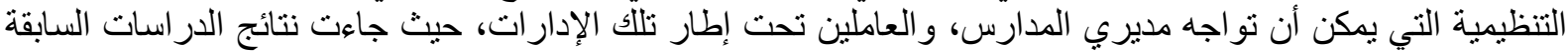

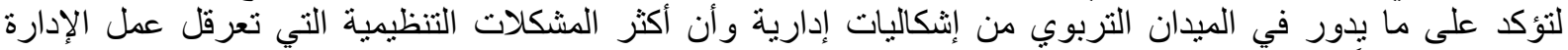

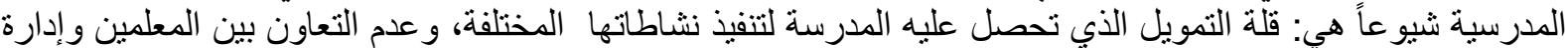

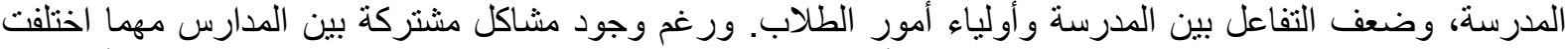

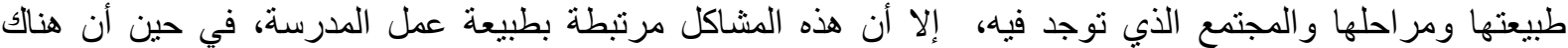

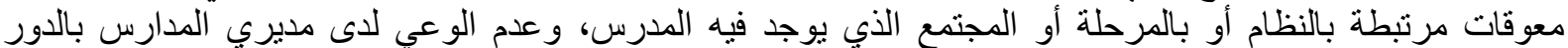

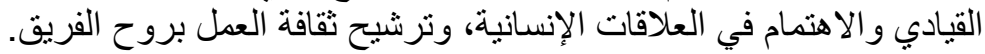

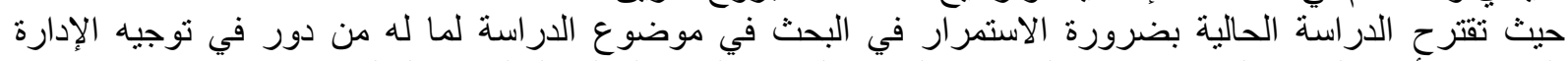

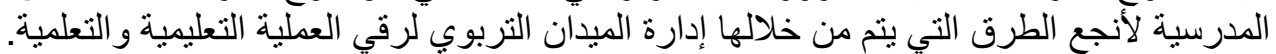

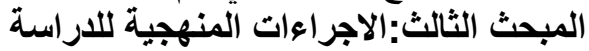

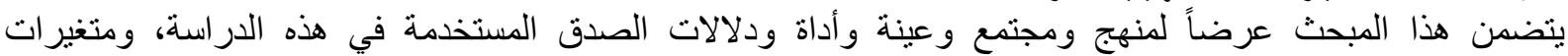

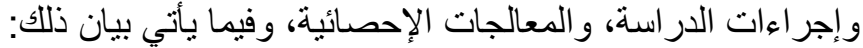

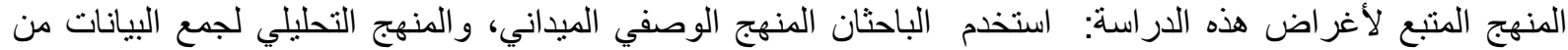

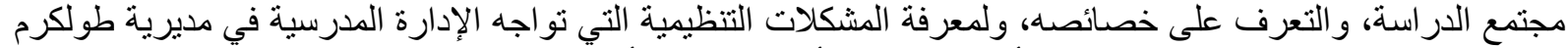

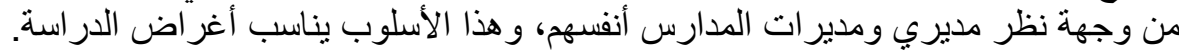

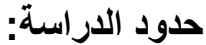
تتأثر نتائج الدر اسة بأربعة محددات هي:

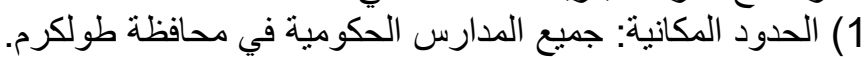
2) الحدود البشرية: سيتم تطبيق هذه الدراسة على مديري ومدير الديرات المدارس الحكومية في محافظة طولكرم و البالغ عدهم

$$
\text { 3)الحدود الزمانية: تم إجر اء هذه الدراسة في الفصل الأول من العام الدراسي (2021/2020) }
$$

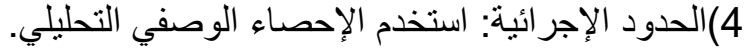

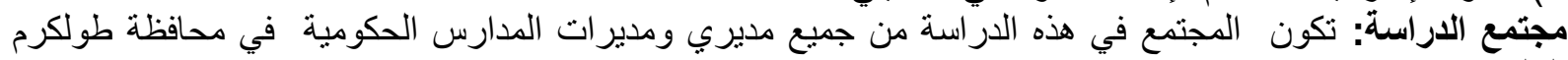

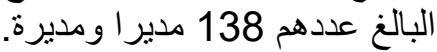

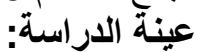

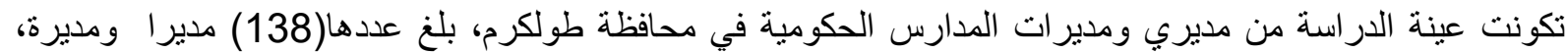

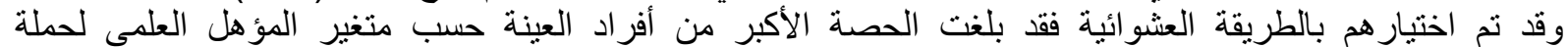

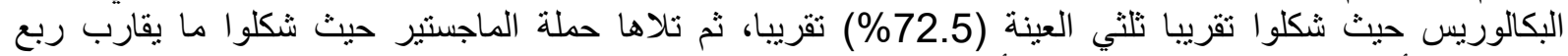

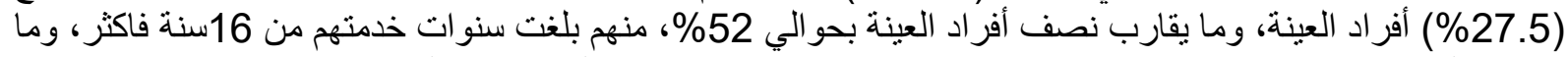

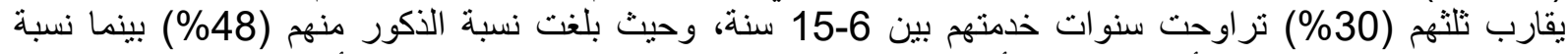

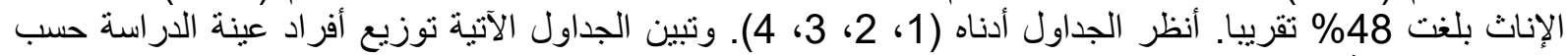

الجدول (1) نوزيع عينة الدراسة حسب متغير الجنس

\begin{tabular}{|c|c|c|}
\hline النسبة المئوية\% & التكر ارات & الجنس \\
\hline 48 & 66 & ذكر \\
\hline 52 & 72 & أنتى \\
\hline 100 & 138 & المجموع \\
\hline
\end{tabular}

يتبين من الجدول السابق أن 48\% من عينة الدر اسة من الذكور و52\% من العينة من الإناث. 


\begin{tabular}{|c|c|c|c|}
\hline \multicolumn{4}{|c|}{ 2-متغير الموقع الجغرافي للمدرسة الدة حسب متغير الموقع الجغر افي للمدرسة } \\
\hline |النسبة المئوية\% & التكر ارات & الموقع الجغر افي & \\
\hline 62.5 & 86 & مدينة & \\
\hline 37.5 & 52 & قرية & \\
\hline 100 & 138 & المجموع & \\
\hline
\end{tabular}

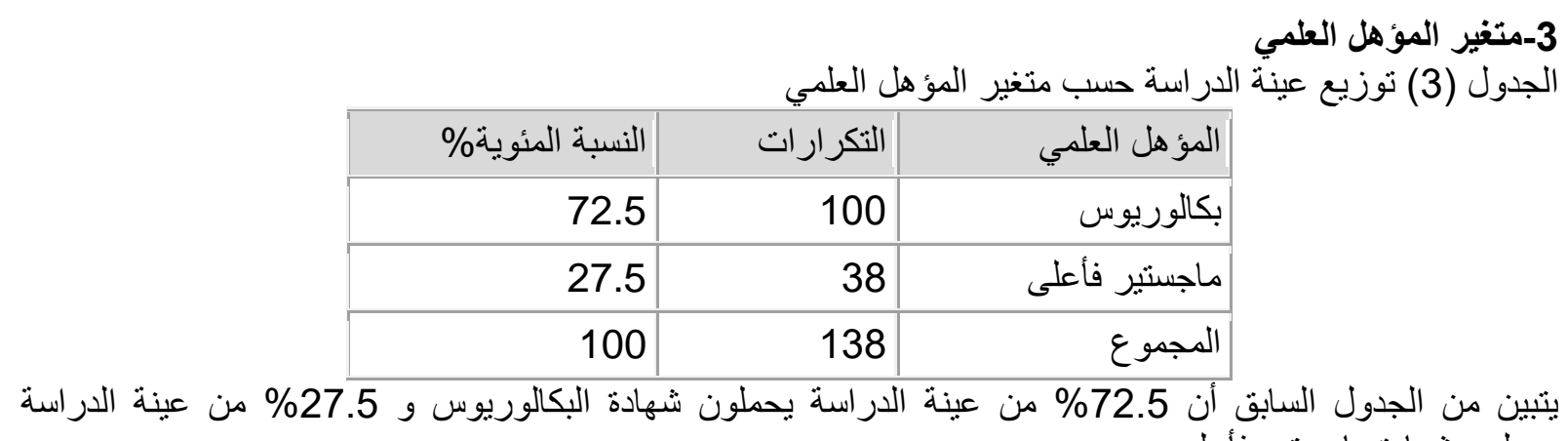
يحملون شهادة ماجستير فأعلى. 4-متفير الخبرة الإدارية الجدول (4) توزيع عينة الدراسة حسب متغير الخبرة الإدارية

\begin{tabular}{|c|c|c|}
\hline النسبة المئويةه\% & التكر ار ات & | الخبرة \\
\hline 17.5 & 25 & من 1 - 5 سنوات \\
\hline 30 & 41 & من 6 - 15 سنوات \\
\hline 52.5 & 72 & أكثر من 15 سنوات \\
\hline 100 & 138 & المجموع \\
\hline
\end{tabular}

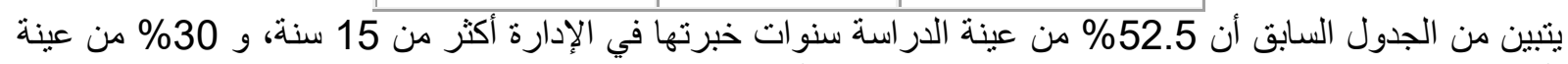
الدر اسة سنوات خدمنها من 6 - 15 سنة، و 17.5 عين 17.5 من العينة سنوات خدمنها من 1 - 5 سنوات الإدات

أداة الدراسة: قام الباحثان بنطوير أداة الدراسة لجمع البيانات المتعلقة بموضوع الدراسة بعد الاطلاع على الدراسات

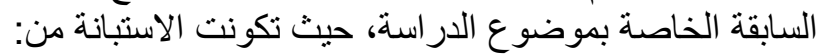

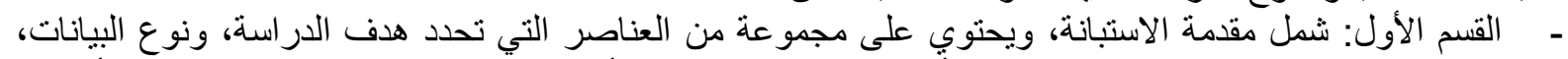

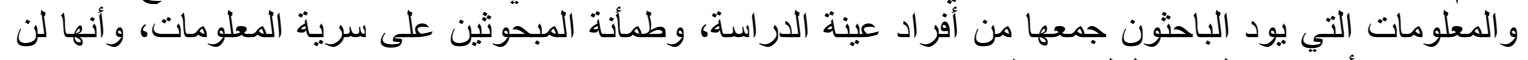

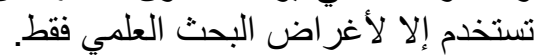

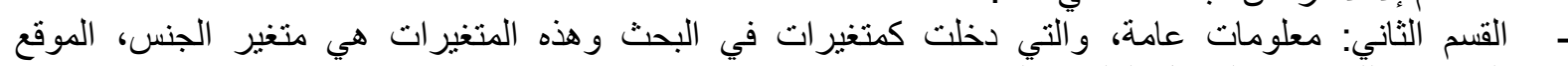

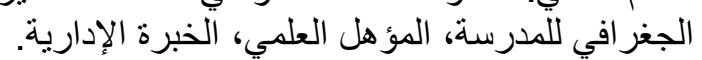

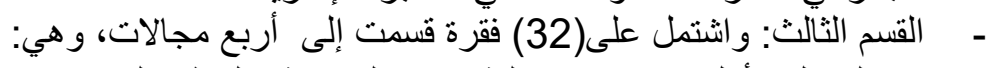

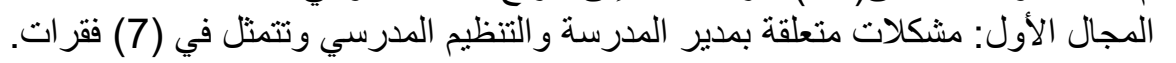

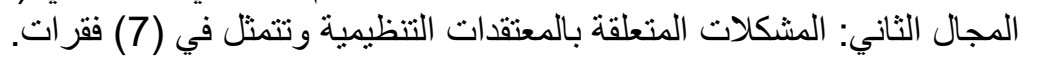

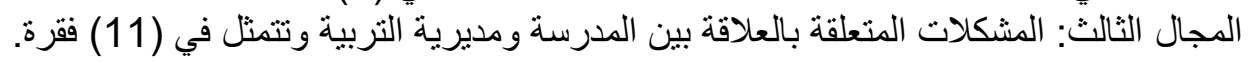

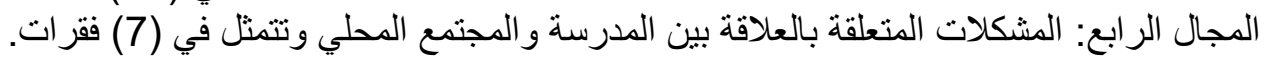


هذا وقد تم تصميم الاستبانة على أساس مقياس ( ليكرت ) خماسي الأبعاد، وبناء عليه قد بينت الفقرات، وأعطيت

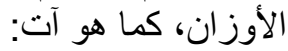

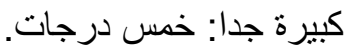

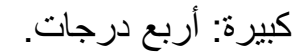
متوسطة: ثلاثلث درجات.

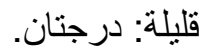
قليلة جدا: درجة و واحدة. وبذلك تكون أعلى درجة في المقياس =5 × 33=165، و أقل درجة =1 333=33.

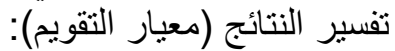
حيث يتم تحويل المتوسطات الحسابية إلى نسب مئوية، وتفسر النتائج على هذا الأساس وفق المعيار الآتي للمو افقة:

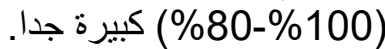
(\%60-\%79.9) (\%)

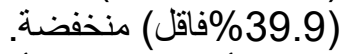

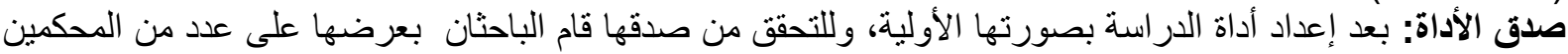

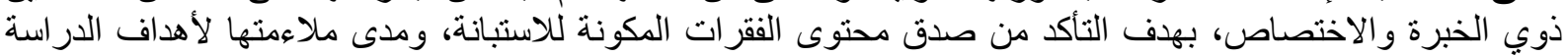

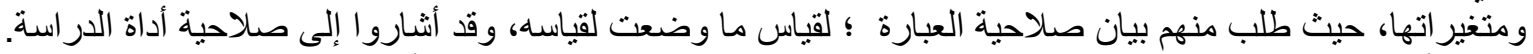

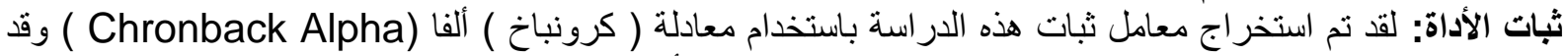
بلغت قيمة معامل الثبات (85.7\%) و هو معامل ثبات جيد جدا يفي بأغر اض البحث العلمي.

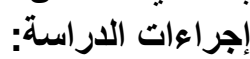

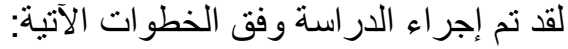
• • • • •

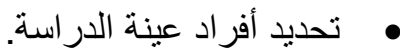

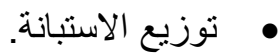
تجميع الاستبانة من أفراد العينة، وترميز ها، وإدخالها إلى الحاسوب، ومعالجتها إحصائيا باستخدام البرنامج

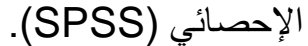

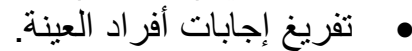
استخر اج النتائج وتحليلها ومناقتشتها.

$$
\begin{aligned}
& \text { تصميم الاراسة: }
\end{aligned}
$$

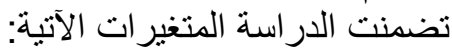

$$
\begin{aligned}
& \text { 1- المتغير ات المستقلة وتشنمل على: الأني: } \\
& \text { - الجنس وله مستويان: } \\
& \text { - } \\
& \text { • مدينة التر } \\
& \text { مرية } \\
& \text { ـ المؤهل العلمي وله مستويان: } \\
& \text { ماجستير فأعلى الإدئ } \\
& \text { - الخبرة الإدارية ولها ثنلاث مستويات: } \\
& \text { • من } 1 \text { - } 5 \text { سنوات. } \\
& \text { • } \\
& \text { • أكثر من } 15 \text { سنة. }
\end{aligned}
$$




\section{ORGANIZATIONAL CHALLENGES FACING SCHOOL ADMINISTRATORS IN}

TULKAREM DIRECTORATE FROM THE POINT OF VIEW OF THE SCHOOL

\section{PRINCIPALS THEMSELVES}

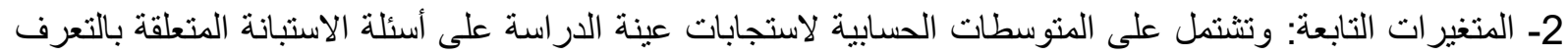

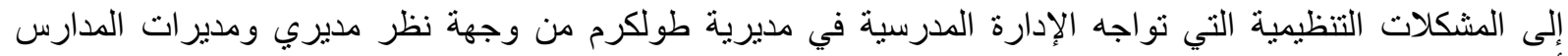

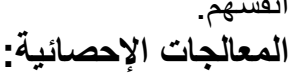
من أجل معالجة البيانات استخدت برنامج الرزم الإحصائية للعلوم الاجتماعية (SPSS) وذلك باستخدام المعالجات

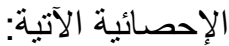

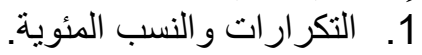

2. 2. المتوسطات والانحر افات المعيارية.

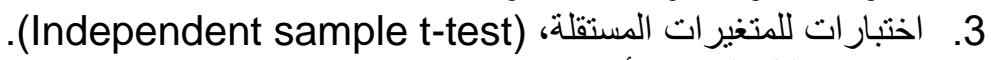

4. اختبار تحليل التباين الأحادي، ( One Way ANOVA ) (

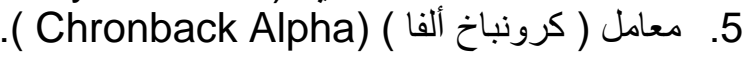

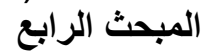

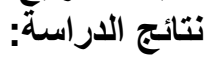

أولا-- النتائج المتعلقة بسؤال الدراسة الأول.

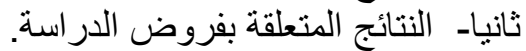

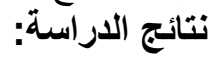

هدفت هذه الدر اسة إلى التعرف على المشكلات التنظيمية التي تو اجه الإدارة المدرسية في مديرية طولكرم شمال فلسطين،

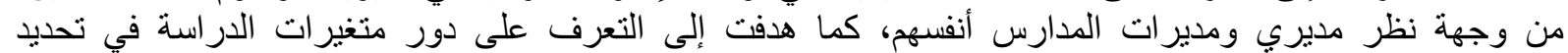

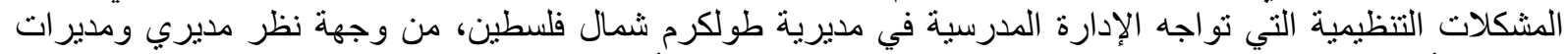

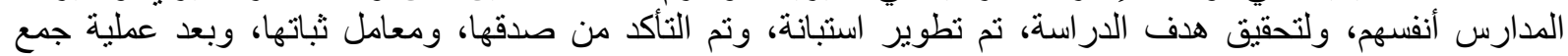

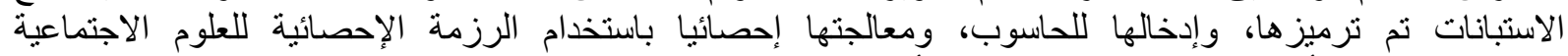
(SPSS)

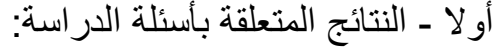
ما هي المشكلات التنظيمية التي تواجه الإدارة المدرسية في مديرية طولكرم شمال فلسطين من وجهة نظر مديري

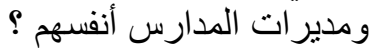
حيث تم استخر اج المتوسطات الحسابية، و النسب المئوية لفقرات الدراسة، ومن ثم ترتييها تنازليا وفق المتوسط الحسابي، واعتمد الباحثان المستويات الآتية للتقدير :

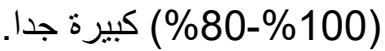
(\%60-\%79.9) (\%)

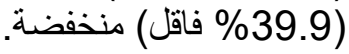

وفيما يأتي جداول تبين هذه النتائج وفق مجالاتها:

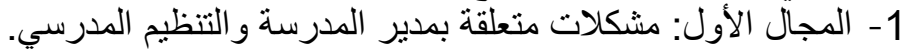

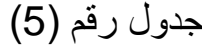
المنوسطات الحسابية، والانحر افات المعيارية، والنسب المئوية، ودرجة الموافقة لفقرات المجال الأول مرتبة تنازليا وفق

\begin{tabular}{|c|c|c|c|c|c|c|}
\hline درجة المو افقة & المئوية & الحسابي & |الانحر | & الفقرة & فرقانة & الترنيب \\
\hline كبيرة & $\begin{array}{r}68.2 \\
\%\end{array}$ & $\begin{array}{r}3.410 \\
3\end{array}$ & $\begin{array}{r}1.018 \\
72\end{array}$ & قالمستجدات & 2 & 1 \\
\hline
\end{tabular}




\begin{tabular}{|c|c|c|c|c|c|c|}
\hline كبيرة & $\begin{array}{r}61.5 \\
\%\end{array}$ & $\begin{array}{r}3.076 \\
9\end{array}$ & $\begin{array}{r}1.155 \\
87\end{array}$ & 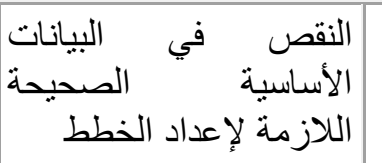 & 5 & 2 \\
\hline كبيرة & $\begin{array}{r}61.5 \\
\%\end{array}$ & $\begin{array}{r}3.076 \\
9\end{array}$ & $\begin{array}{r}1.178 \\
42\end{array}$ & |المدرسة للقيام بمهام إدارة لمدير & 1 & 3 \\
\hline كبيرة & $\begin{array}{r}60.5 \\
\%\end{array}$ & $\begin{array}{r}3.025 \\
6\end{array}$ & $\begin{array}{r}1.087 \\
90\end{array}$ & |لمثركلة لمدير المدرسة المباء و المهام & 3 & 4 \\
\hline كبيرة & $\begin{array}{r}60.5 \\
\%\end{array}$ & $\begin{array}{r}2.769 \\
2\end{array}$ & $\begin{array}{r}1.012 \\
07\end{array}$ & 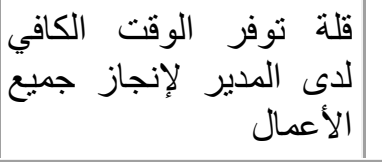 & 7 & 5 \\
\hline منوسطة & $\begin{array}{r}54.9 \\
\%\end{array}$ & $\begin{array}{r}2.743 \\
6\end{array}$ & $\begin{array}{r}1.250 \\
64\end{array}$ & |لمعاون لمدير المدرسة الإداري & 6 & 6 \\
\hline منوسطة & $\begin{array}{r}52.8 \\
\%\end{array}$ & $\begin{array}{r}2.641 \\
0\end{array}$ & $\begin{array}{r}0.959 \\
36\end{array}$ & | قلة استقر ار التظظيم داخل الإجاز & 4 & 7 \\
\hline متوسطة & $\begin{array}{r}59.3 \\
\%\end{array}$ & $\begin{array}{r}2.963 \\
4\end{array}$ & $\begin{array}{r}0.586 \\
01\end{array}$ & \multicolumn{3}{|c|}{ الدرجة الكلية للمجال الأول } \\
\hline
\end{tabular}

$$
\text { يتبين من الجدول رقم (5) السابق: }
$$

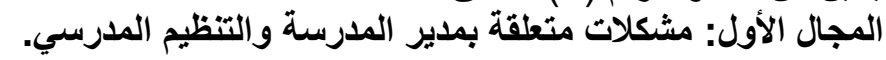

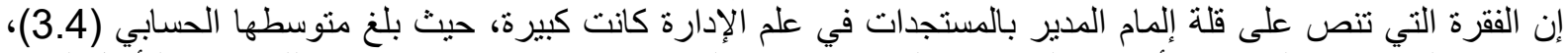

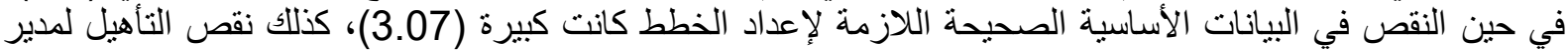

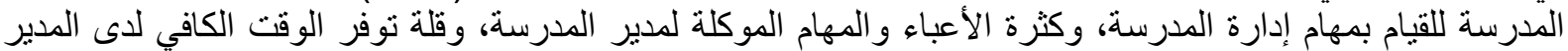

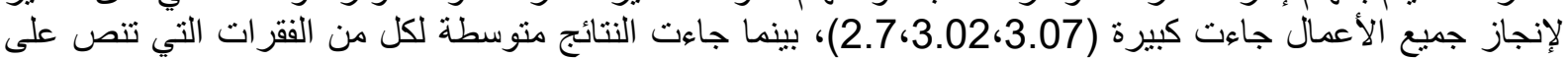

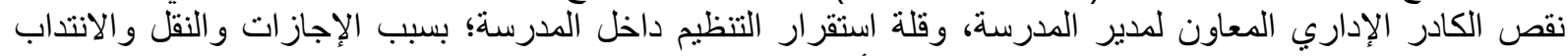
(2.6،2.7)، كما يلاحظ من خلال الجدول السابق أن المنوسط العام لاستجابات المبحوثين قد بلغت (2.96) وهي منوسطة. 2-المجال الثاني: المشكلات المتعلقة بالمعتقدات التنظيمية .

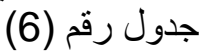
المتوسطات الحسابية، والانحر افات المعيارية، و النسب المئوية، ودرجة المو افقة لفقرات المجال الثاني مرتبة تنازليا وفق

\begin{tabular}{|c|c|c|c|c|c|c|}
\hline الموجة & المئوية & الحسابي & الانحر افياري & الفقرة & |رقيا & تيب \\
\hline كبيرة & $72.8 \%$ & 3.6410 & 1.22447 & | أعمالهم ومبادر التهم & 6 & 1 \\
\hline كبيرة & $71.8 \%$ & 3.5897 & 1.29204 & من الصنلاحيات تيض في المدرسة & 3 & 2 \\
\hline كبيرة & $71.3 \%$ & 3.5641 & 1.09532 & 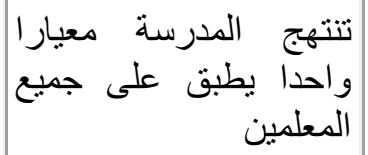 & 4 & 3 \\
\hline
\end{tabular}




\begin{tabular}{|c|c|c|c|c|c|c|}
\hline كبيرة & $69.7 \%$ & 3.4872 & 1.02268 & الثقافة المحفزة الادارة اللابداعرسية & 7 & 4 \\
\hline كبيرة & $66.2 \%$ & 3.3077 & 1.15060 & 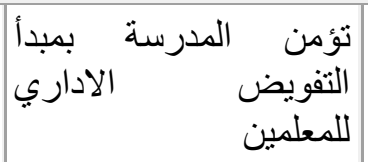 & 2 & 5 \\
\hline كبيرة & $63.7 \%$ & 3.1842 & 1.41144 & لمشتعة التعليم المعلمون بالو لاء & 1 & 6 \\
\hline كبيرة & $60.5 \%$ & 3.0256 & 1.30761 & لتمد المعتق معتقدات المعلمين & 9 & 7 \\
\hline مت متو مط & $57.9 \%$ & 2.8974 & 1.14236 & تعزيز النمو المهني للمعلم & 10 & 8 \\
\hline كبيرة & $66.8 \%$ & 3.3388 & .75058 & لمجال الثاني & الك & الدر. \\
\hline
\end{tabular}

يتبين من الجدول رقم (6) السابق:

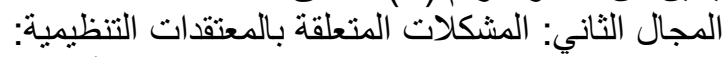

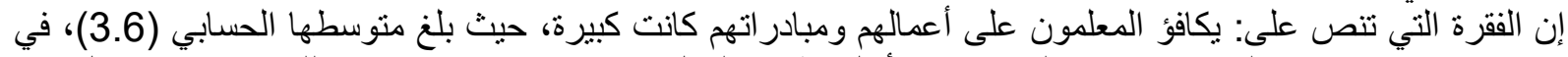

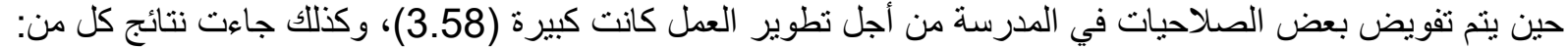

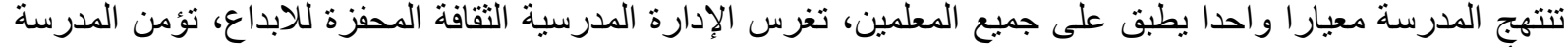

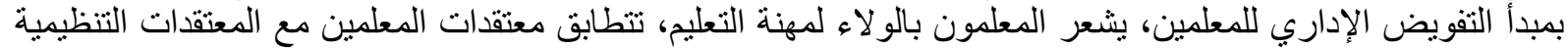

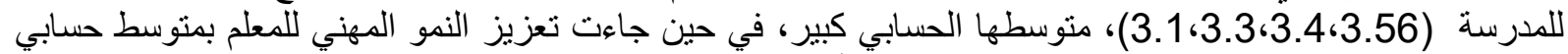
متوسط (2.8)، كما يلاحظ من خلال الجدول السابق أن المتوسط العام لاستجابات المبحوثين قد بلغت النت (3.3)، وهي 3-المجال الثالث: مجال المشكلات المتعقة بالعلاقة بين المدرسة ومديرية التربية.

جدول رقم (7) (7) المنوسطات الحسابية، و الانحر افات المعيارية، و النسب المئوية، ودرجة الموافقة لفقرات المجال الثالث مرنبة تنازليا وفق المتوسط الحسابي

\begin{tabular}{|c|c|c|c|c|c|c|}
\hline درجة المو افقة & المئوية & المتسابي & الانحر اف المياري & الفقرة & رقاستبانة في & الترتيب \\
\hline كبيرة جدا & $85.6 \%$ & 4.2821 & .64680 & 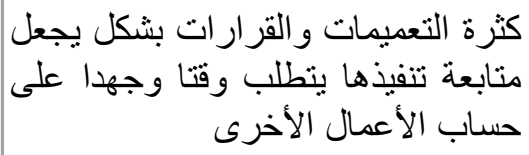 & 2 & 1 \\
\hline كبيرة جدا & $84.1 \%$ & 4.2051 & .92280 & والتعليمات. المدارس بالتقيد الحرفي بالنظم & 6 & 2 \\
\hline كبيرة جدا & $80.5 \%$ & 4.0256 & .90284 & والمستو يات العليا للإدارة. & 4 & 3 \\
\hline كبيرة جدا & $80 \%$ & 4.0000 & 1.07606 & يصعب تطبيقها و اقعيا في المدارس ملى مثالية & 3 & 4 \\
\hline كبيرة & $77.4 \%$ & 3.8718 & .95089 & الإصلاح الأعطال بالمختبر ات. الفنين النصصين & 9 & 5 \\
\hline
\end{tabular}




\begin{tabular}{|c|c|c|c|c|c|c|}
\hline كبيرة & $76.4 \%$ & 3.8205 & .99662 & المعاملات الإبعارية. الروتيني عند إنجاز & 8 & 6 \\
\hline كبيرة & $72.8 \%$ & 3.6410 & 1.06344 & 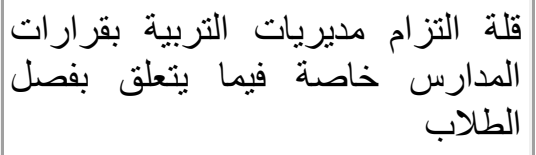 & 5 & 7 \\
\hline كبيرة & $64.1 \%$ & 3.2051 & 1.30141 & الصنادرة وضن المديرية. & 1 & 8 \\
\hline كبيرة & $63.6 \%$ & 3.1795 & 1.07292 & المعلمين. في تلبية احتياجات المدارس من & 7 & 9 \\
\hline كبيرة & $61 \%$ & 3.0513 & 1.19095 & عاتقة. & 11 & 10 \\
\hline متوسطة & $54.9 \%$ & 2.7436 & 1.25064 & | بر أبر اء التشكيلات المدرسة. & 10 & 11 \\
\hline كبيرة & $72.8 \%$ & 3.6387 & .49288 & \multicolumn{3}{|c|}{ الدرجة الكلية للمجال الثالث } \\
\hline
\end{tabular}

$$
\text { يتبين من الجدول رقم (7) السابق: }
$$

المجال الثالث: المشكلات المتعلقة بالعلاقة بين المدرسة ومديرية التربية.

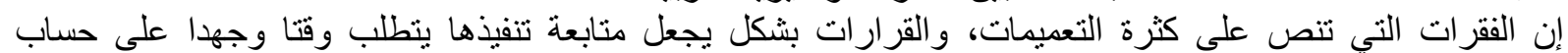

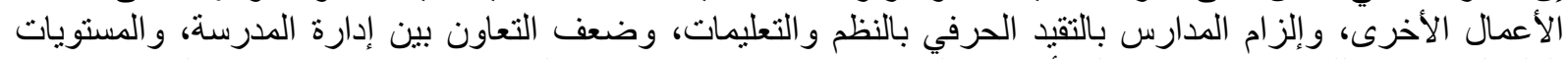

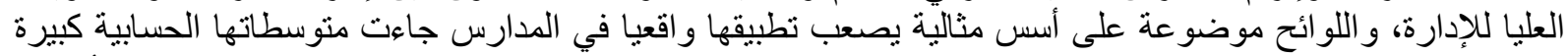

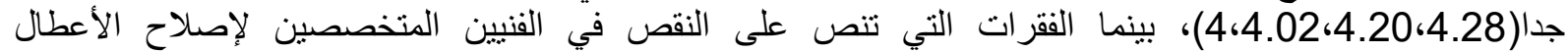

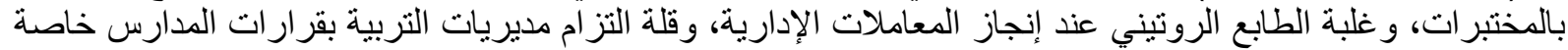

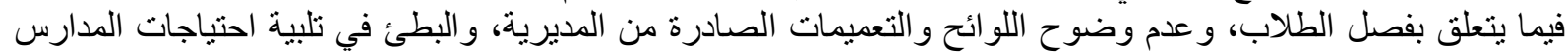

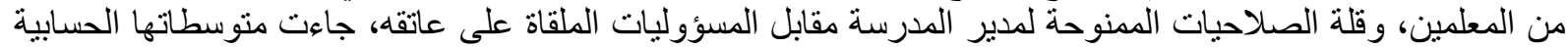

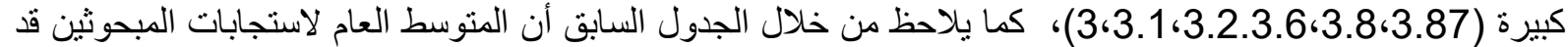

$$
\text { بلغت (3.6) و هي كبيرة. }
$$

4-المجال الرابع: المشكلات المتعلقة بالعلاقة بين المدرسة والمجتمع المحلي.

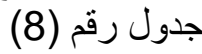

المتوسطات الحسابية، والانحر افات المعيارية، و النسب المئوية، ودرجة الموافقة لفقرات المجال الرابع مرتبة تنازليا وفق

\begin{tabular}{|c|c|c|c|c|c|c|}
\hline المر افقة & المئوية & الحتوسد & الانحرا & الفقرة & رقيا & يب الترت \\
\hline كبيرة جدا & $\begin{array}{l}81.5 \\
\%\end{array}$ & $\begin{array}{l}4.076 \\
9\end{array}$ & $\begin{array}{l}1.010 \\
07\end{array}$ & المعتى النشاطات أولياء الأمور & 3 & 1 \\
\hline كبيرة جدا & $\begin{array}{l}81.5 \\
\%\end{array}$ & $\begin{array}{l}4.076 \\
9\end{array}$ & $\begin{array}{l}1.132 \\
87\end{array}$ & قأبنائهم الطمام أولياء الأمور & 1 & 2 \\
\hline كبيرة & $\begin{array}{l}79.5 \\
\%\end{array}$ & $\begin{array}{l}3.974 \\
4\end{array}$ & $\begin{array}{l}1.087 \\
90\end{array}$ & 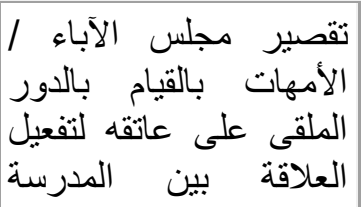 & 2 & 3 \\
\hline
\end{tabular}




\begin{tabular}{|c|c|c|c|c|c|c|}
\hline & & & & & & \\
\hline & & & & و المجتمع المحلي & & \\
\hline كبيرة & $\begin{array}{l}75.8 \\
\%\end{array}$ & $\begin{array}{l}3.789 \\
5\end{array}$ & $\begin{array}{l}.9907 \\
1\end{array}$ & 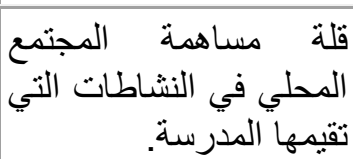 & 6 & 5 \\
\hline كبيرة & $\begin{array}{l}72.8 \\
\%\end{array}$ & $\begin{array}{l}3.641 \\
0\end{array}$ & $\begin{array}{l}1.180 \\
70\end{array}$ & قإدارة المدرسة على مكاتبات & 7 & 6 \\
\hline كبيرة & $\begin{array}{l}71.3 \\
\%\end{array}$ & $\begin{array}{l}3.564 \\
1\end{array}$ & $\begin{array}{l}1.209 \\
50\end{array}$ & لاستداعاء المدرسةة. أولياء الأمور & 4 & 8 \\
\hline كبيرة & $\begin{array}{l}64.2 \\
\%\end{array}$ & $\begin{array}{l}3.210 \\
5\end{array}$ & $\begin{array}{l}1.017 \\
63\end{array}$ & 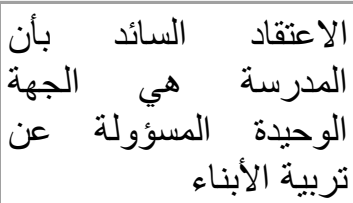 & 5 & \\
\hline كبيرة & $\begin{array}{l}75.3 \\
\%\end{array}$ & $\begin{array}{l}3.767 \\
0\end{array}$ & $\begin{array}{l}.6713 \\
6\end{array}$ & (1) "I & & \\
\hline
\end{tabular}

يتبين من الجدول رقم (8) السابق:

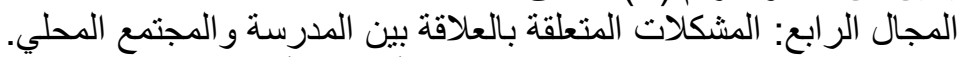

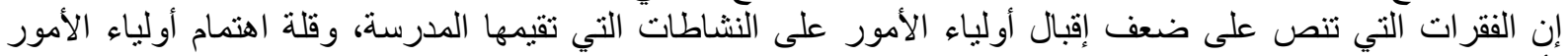

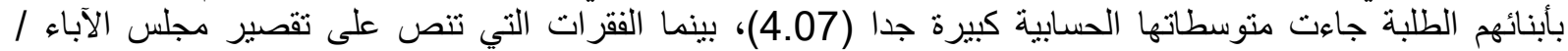

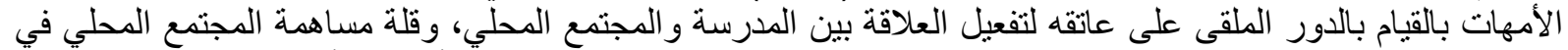

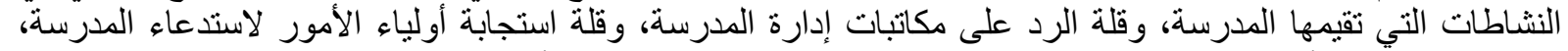

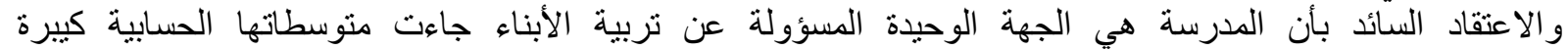

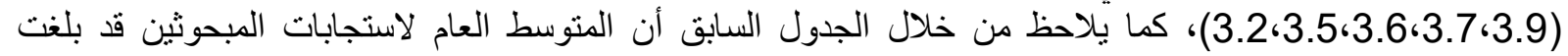

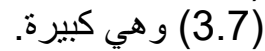

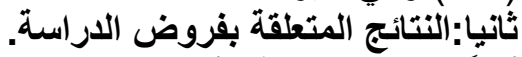

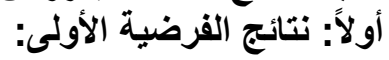

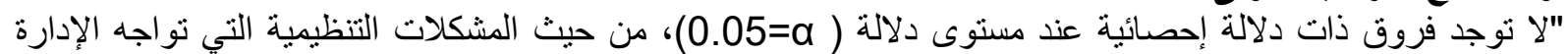

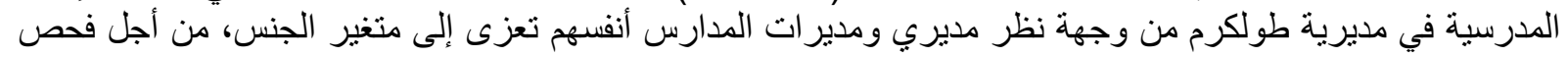

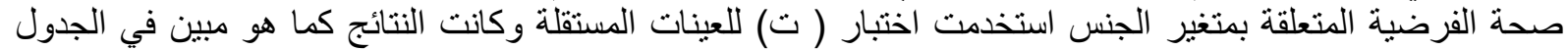

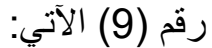
الجدول (9) نتائج اختبار ( ت) لدألانة الفروقي، من حيث المشكلات التنظيمية التي تواجه الادارة المدرسية في مديرية

\begin{tabular}{|c|c|c|c|c|c|c|}
\hline \multirow{2}{*}{ الدلالة } & \multirow{2}{*}{ قيمة (ت) } & \multicolumn{2}{|c|}{ أنثى(العدد=72) } & \multicolumn{2}{|c|}{ ذكر (العدد=66) } & \multirow{2}{*}{ المجال } \\
\hline & & المتوسط & الانحر اف & المتوسط & الانحر اف & \\
\hline 0.033 & 2.213 & 2.6667 & 0.66543 & 3.0952 & 0.50585 & المجال الأول \\
\hline 0.346 & 0.954 & 3.1667 & 0.78032 & 3.4153 & 0.73892 & المجال الثاني \\
\hline 0.093 & 1.727 & 3.4394 & 0.49007 & 3.7273 & 0.47640 & المجال الثالث \\
\hline 0.293 & 1.067 & 3.5952 & 0.52695 & 3.8434 & 0.72221 & المجال الر ابع \\
\hline 0.063 & 1.914 & 3.2170 & 0.42896 & 3.5203 & 0.46812 & الدرجة الكلية \\
\hline
\end{tabular}




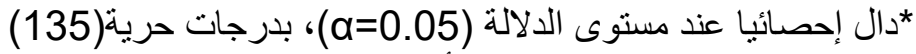

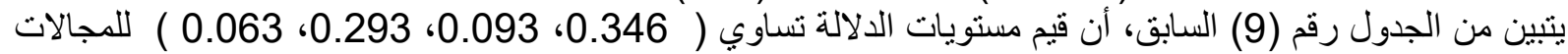

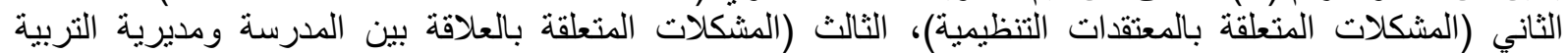

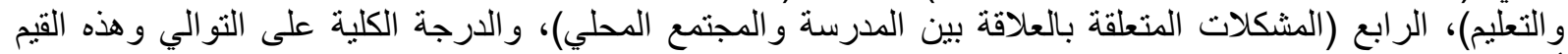

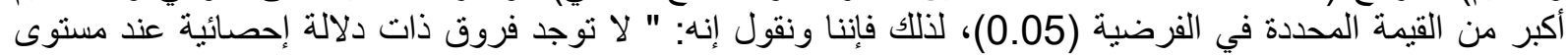

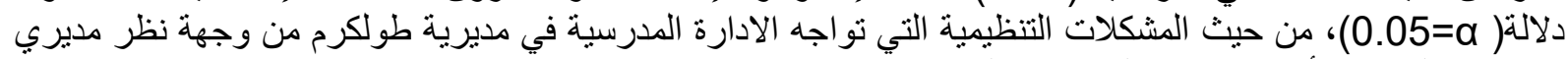

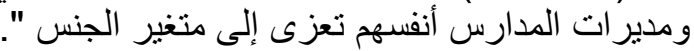

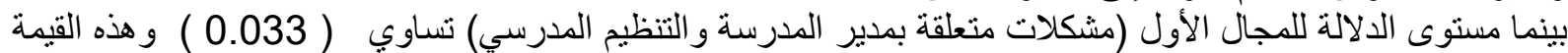

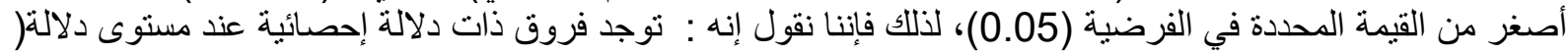

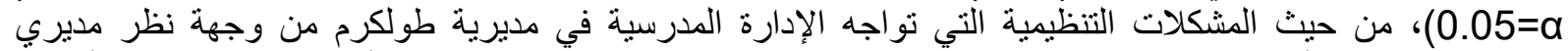

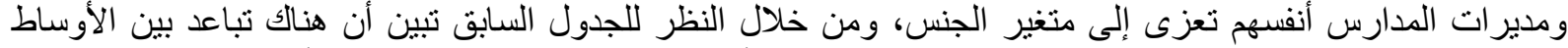

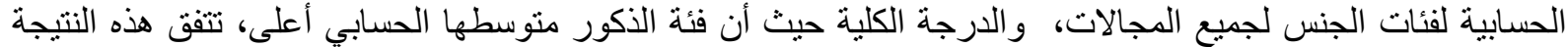

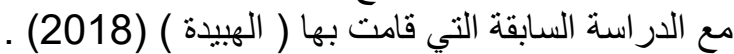

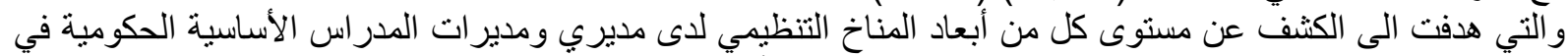

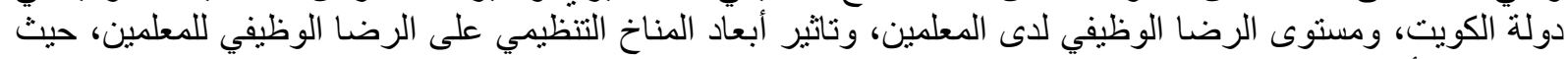
تبين وجود أثر للمناخ التنظيمي على مستوى الرضا لترفيا الوظيفي للمعلمين. ثانياً. نتائج الفرضية الثانية:

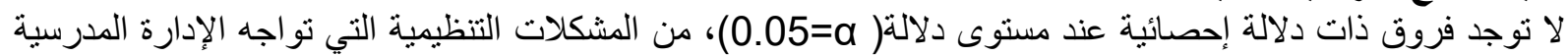

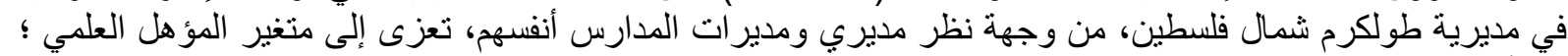
من أجل فحص صحة الفرضية المتعلقة بمتغير المؤهل العلمي استخدم اختبار ( ت) للعينات المستقلة، وكانت النتائج كما هو مبين في الجدول رقم (10) الآتي:

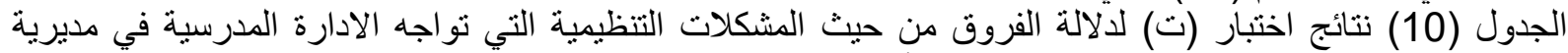

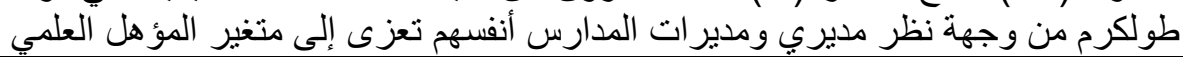

\begin{tabular}{|c|c|c|c|c|c|c|}
\hline \multirow{2}{*}{ الدلالة } & \multirow{2}{*}{ قيمة (ت) } & \multicolumn{2}{|c|}{ ماجستير فأعلى(العدد=38) } & \multicolumn{2}{|c|}{ بكالوريوس(العدد=100) } & \multirow{2}{*}{ 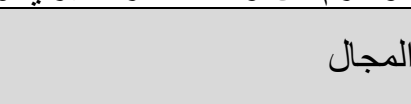 } \\
\hline & & المتوسط & الانحر اف & المتوسط & الانحر اف & \\
\hline .452 & -.761 & 3.0779 & .52824 & 2.9184 & .61035 & المجال الأول \\
\hline .126 & -1.564 & 3.6331 & .61296 & 3.2232 & .77755 & المجال الثاني \\
\hline .250 & -1.168 & 3.7851 & .51309 & 3.5812 & .48190 & المجال الثالث \\
\hline .996 & .005 & 3.7662 & .83854 & 3.7673 & .61149 & المجال الر ابع \\
\hline .256 & -1.153 & 3.5656 & .51185 & 3.3725 & .45426 & الدرجة الكلية \\
\hline
\end{tabular}

يتبين من الجدول رقم (10) السابق، أن قيم مستويات الدلالة تساوي (

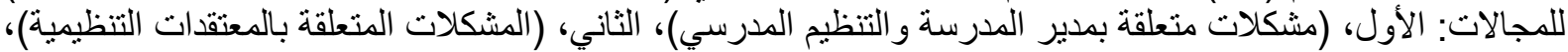

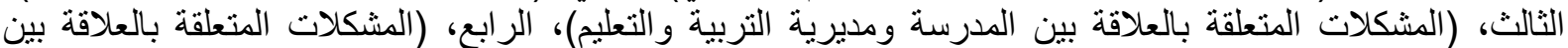

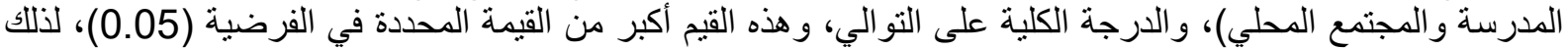

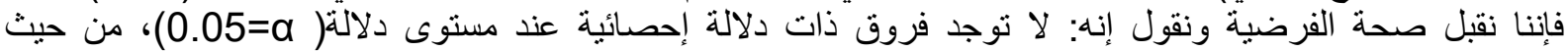

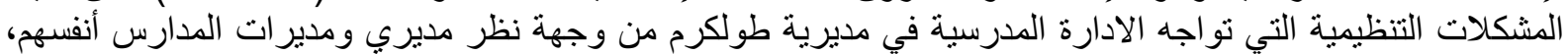

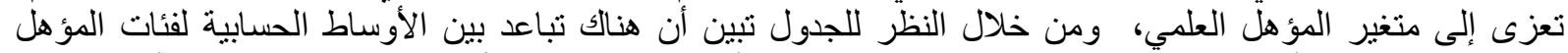

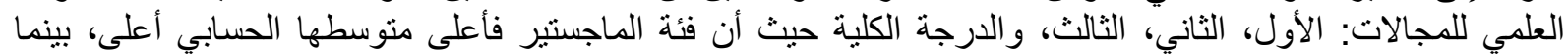

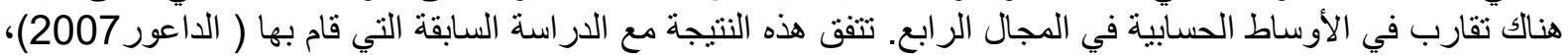

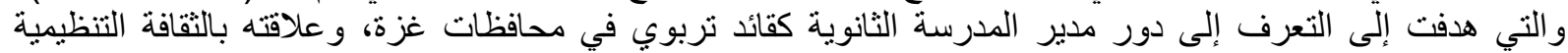

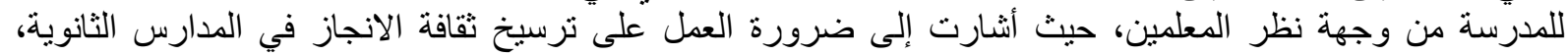

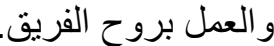
تالثا: نتائج الفرضية الثالثة: لا توجد فروق ذات دلالة إحصائية عند مستوى دلالة ( a=0.05)، من حيث حيث المشكلات التنظيمية التي تواجه الإدارة

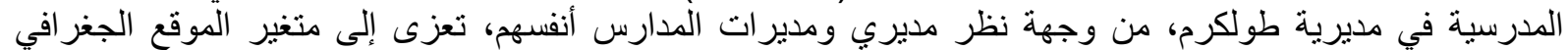

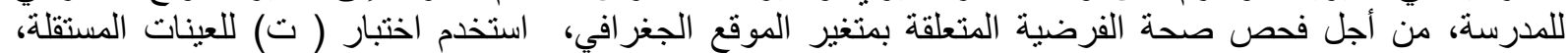
وكانت النتائج كما هو مبين في الجدول رقم (11) الآتي: 


\section{ORGANIZATIONAL CHALLENGES FACING SCHOOL ADMINISTRATORS IN TULKAREM DIRECTORATE FROM THE POINT OF VIEW OF THE SCHOOL PRINCIPALS THEMSELVES}

الجدول (11) نتائج اختبار (ت) لدلالة الفروق من حيث المشكلات التنظيمية التي تواجه الادارة المدرسية في مديرية

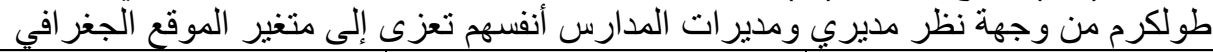

\begin{tabular}{|c|c|c|c|c|c|c|}
\hline \multirow{2}{*}{ مستوى الدلالة } & \multirow{2}{*}{ قيمة (ت) } & \multicolumn{2}{|c|}{ قرية(العدد=52) } & \multicolumn{2}{|c|}{ مدينة (العدد=86) } & \multirow{2}{*}{ 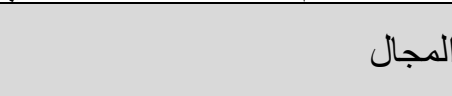 } \\
\hline & & المتوسط & الانحر اف & المتوسط & الانحر اف & \\
\hline .003 & -3.122 & 3.3163 & .45926 & 2.7657 & .56225 & المجال الأول \\
\hline .303 & -1.044 & 3.5064 & .56745 & 3.2450 & .83188 & المجال الثاني \\
\hline .008 & -2.782 & 3.9091 & .37567 & 3.4873 & .49158 & المجال الثالث \\
\hline .032 & -2.226 & 4.0714 & .41838 & 3.5966 & .73110 & المجال الر ابع \\
\hline .005 & -2.974 & 3.7008 & .32180 & 3.2736 & .47881 & الدرجة الكلية \\
\hline
\end{tabular}

*دال إحصائيا عند مستوى الدلالة (a=0.05)، بدرجات حرية(135)

ينبين من الجدول رقم (11) السابق، أن قيمة مستوى الدلالة تساوي ( 0.303 ) للجال الثرال الثاني (المشكلات المتعلقة

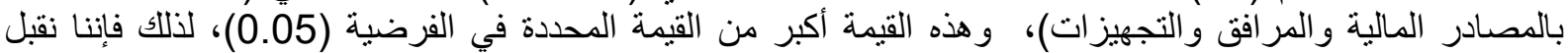

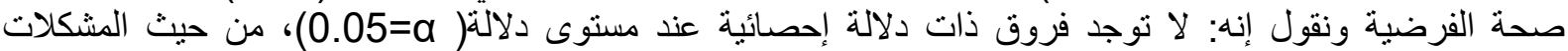

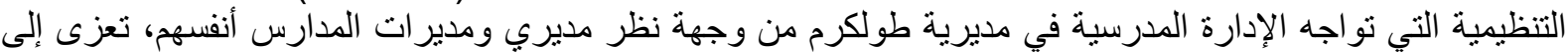
متغير الموقع الجغر افي للمدرسة. بينما قيم مستويات الدالة تساوي ( 0.003، 0.008، 0.032،

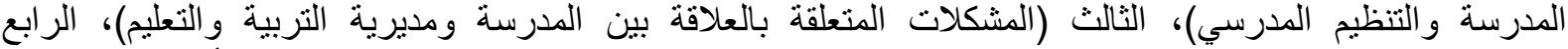

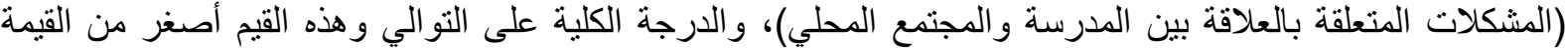

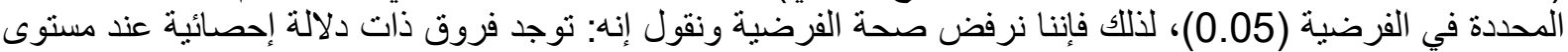

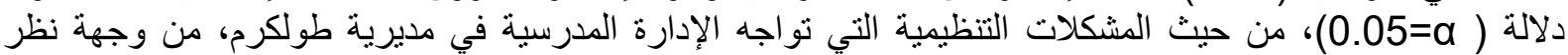

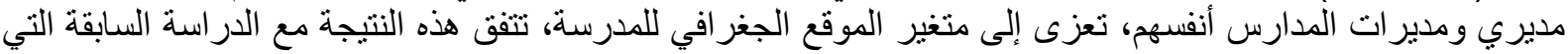

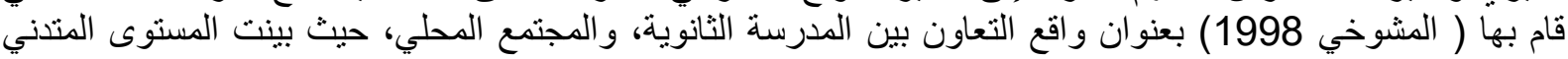

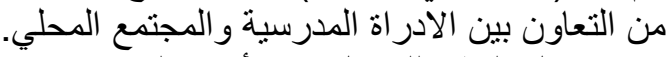

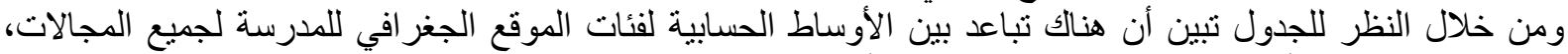

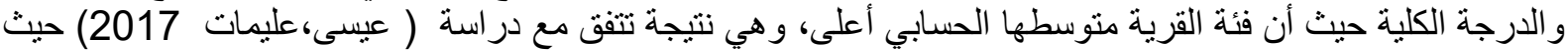

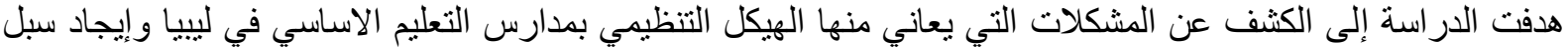
ومفترحات لتطويره حيث برز من أهم المشكلات غياب خريطة تنظيمية للمدرسة بالإضافة إلى ضعف الإن الاهتمام بتميم كادر رإبوائف

رابعا: مناقشة نتائج الفرضية الرابعة: لا نوجد فروق ذات دلالة إحصائية عند مستوى دلالة ( a=م-0.05)، من حيث المشكلات التنظيمية الني تواجه الإدارة

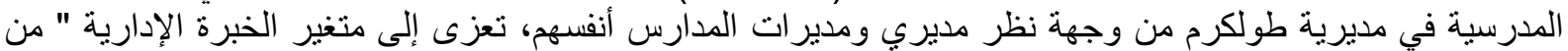

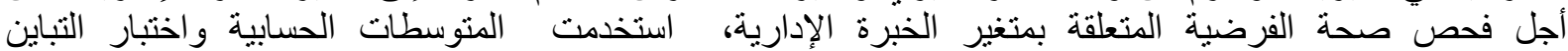

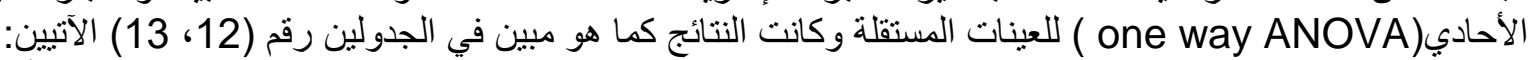

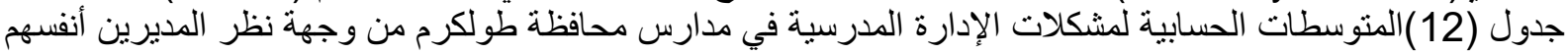
تعزى إلى متغير الخبرة الإدارية

\begin{tabular}{|c|c|c|c|}
\hline أكثر من 10 سنوات & من 12-10 سنوات & من 1-5 سنوات (7) & المجالات \\
\hline 3.0136 & 2.8571 & 2.9796 & المجال الأول \\
\hline 3.2364 & 3.3409 & 3.6429 & المجال الثاني \\
\hline 3.7359 & 3.5455 & 3.4935 & المجال الثالث \\
\hline 3.9524 & 3.5325 & 3.5796 & المجال الرابع \\
\hline 3.4846 & 3.3190 & 3.4239 & الدرجة الكلية \\
\hline
\end{tabular}


يتضح من خلال الجدول (12) أن هنالك فروق في الأوساط الحسابية لفئات الخبرة الإدارية في المجال الأول (مشكلات

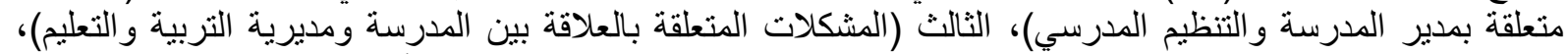

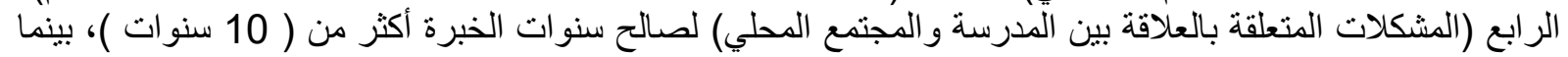

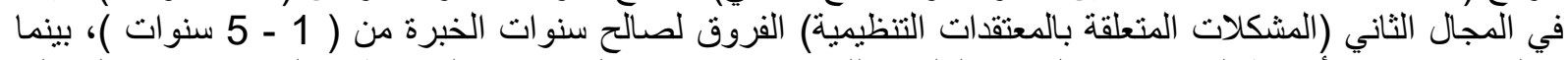

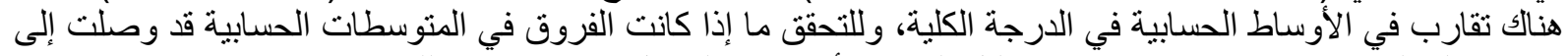

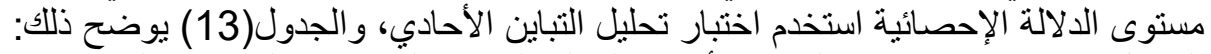

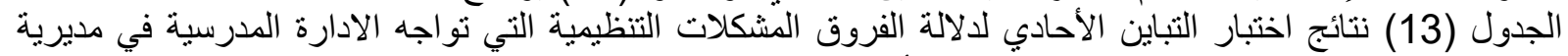
طولكرم من وجهة نظر مديري ومدير ات المدارس أنفسهم تعزى إلى متغير الخبرة الإدارية

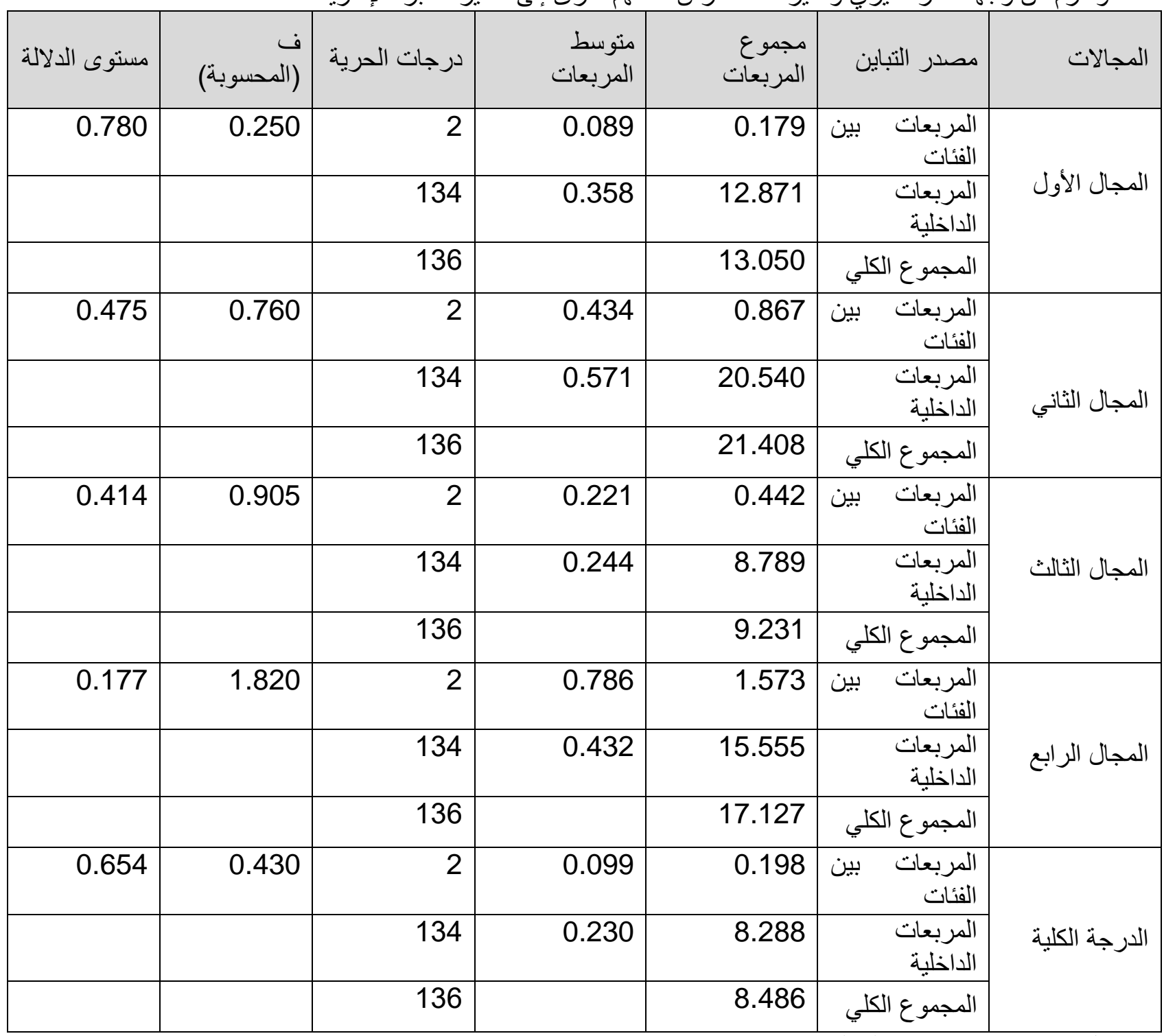

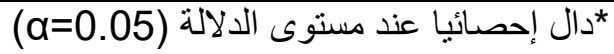

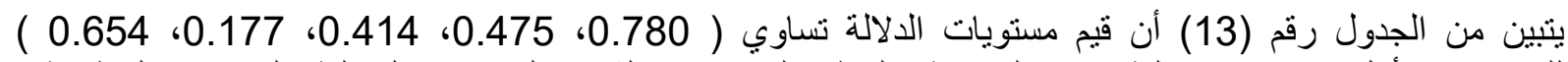

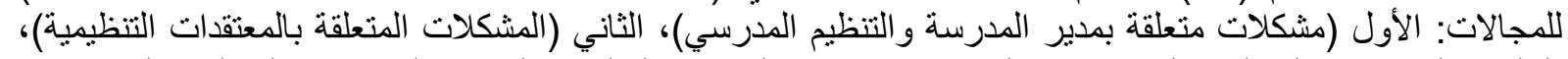

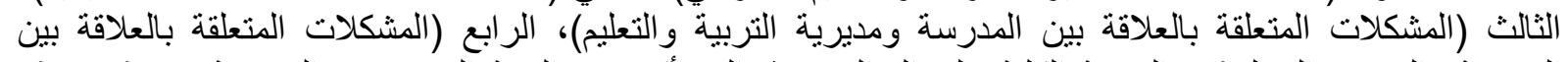

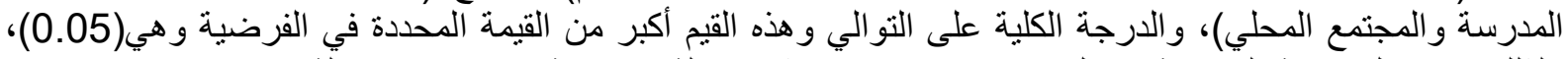

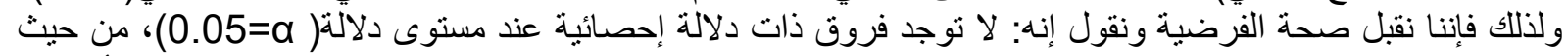

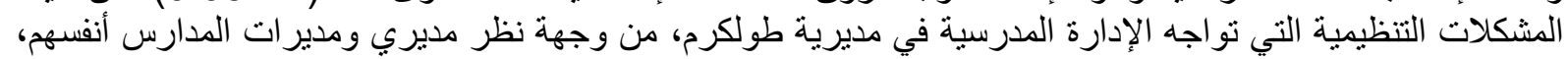

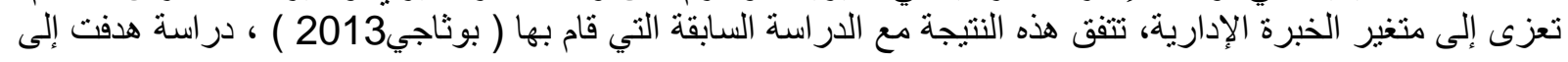




\section{ORGANIZATIONAL CHALLENGES FACING SCHOOL ADMINISTRATORS IN TULKAREM DIRECTORATE FROM THE POINT OF VIEW OF THE SCHOOL PRINCIPALS THEMSELVES}

إصلاح المدرسة في ضوء قيادة مدرسية إبداعية، وأوصت: " بأن مديري الددارس لإيمكن أن يقودوا مدارسهم بطريقة

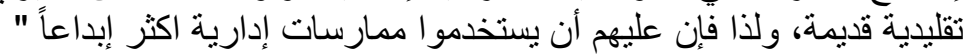

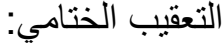
إن الفقرة التي تنص على قلة إلمام المدير بالمستجدات في علم الإدارة كانت كبيرة حيث بلغ منوسطها الحسابي (3.4) في

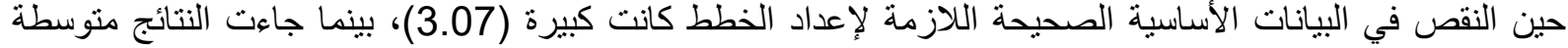

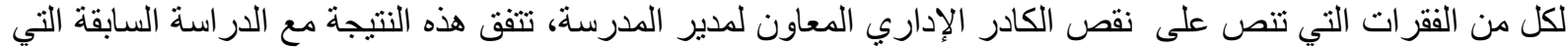

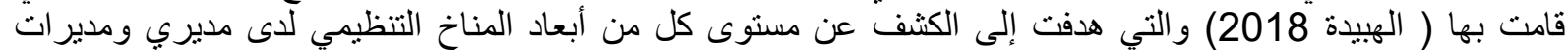

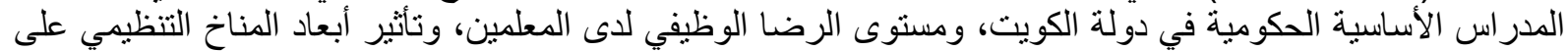

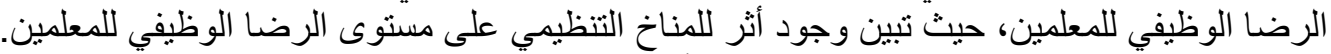

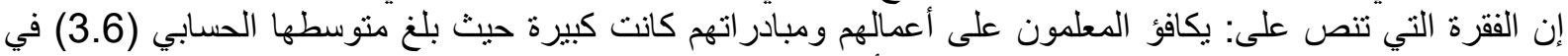

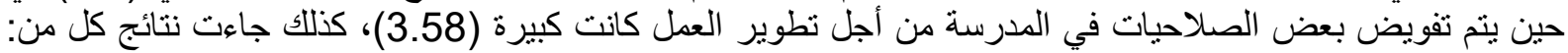

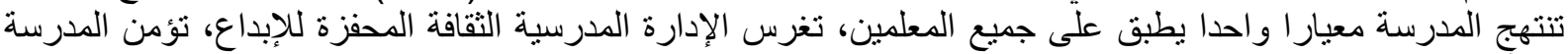

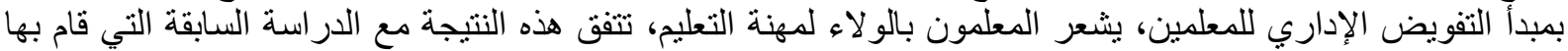

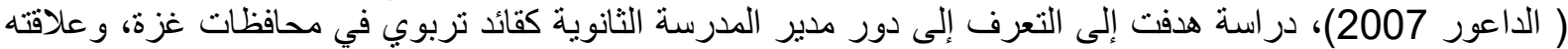
بالثقافة التنظيمية للمدرسة من وجهة نظر المعلمين، حيث أشنارت إلى ضرورة الكئ العمل على ترسيخ ثقافة الإنجاز في المدارس الثانوية والعمل بروح الفريق.

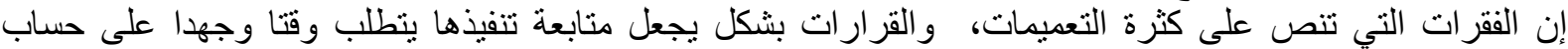

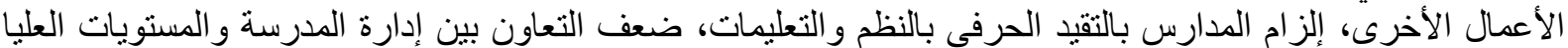

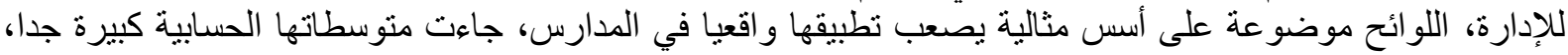

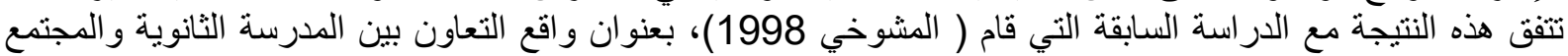

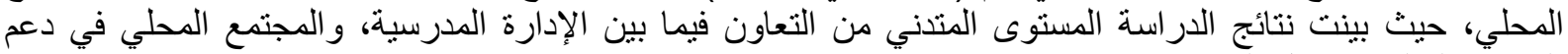
المسيرة التعليمية داخل المدرسة.

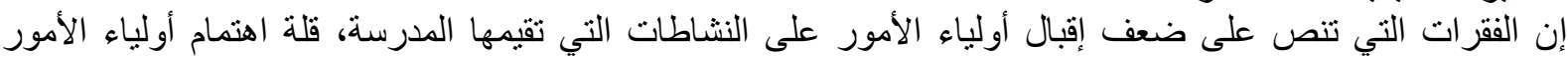

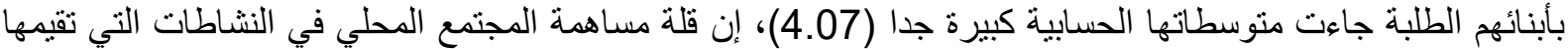

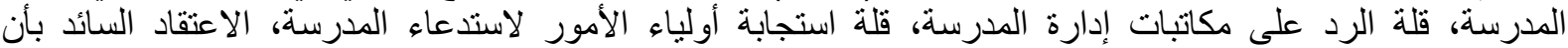

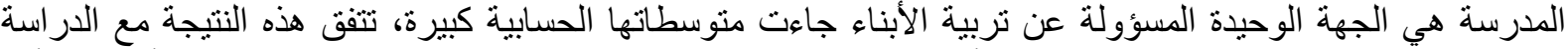

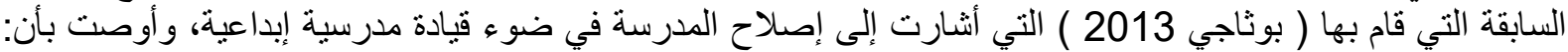

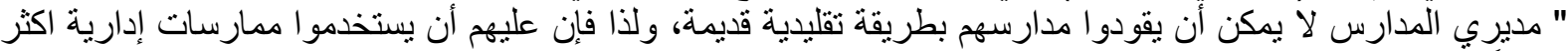

ابداعاً " مديري

خاتمة:

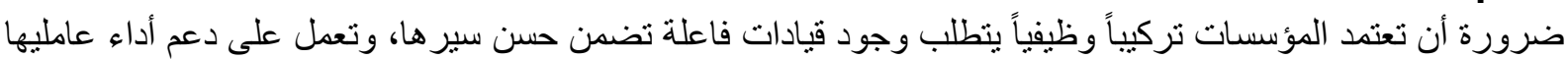

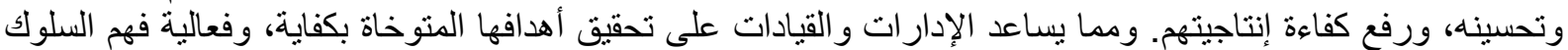

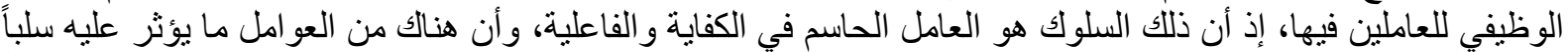

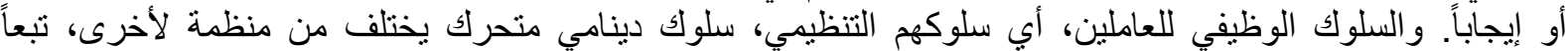

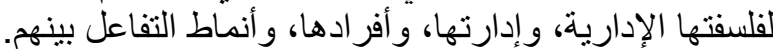

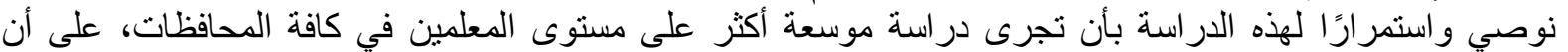

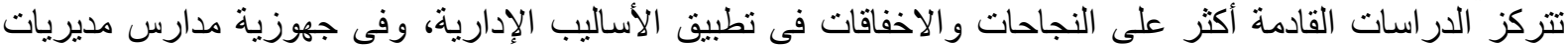

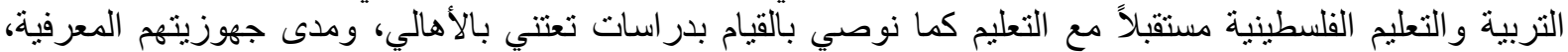

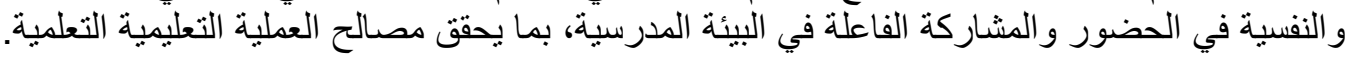

قائمة المراجع العربية

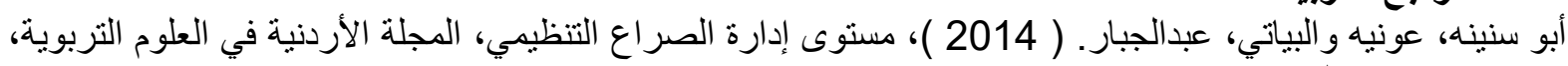

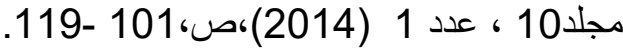

بطاح، أحمد. (2006): قضايا معاصرة في الإدارة التربوية، دار الثروق، التهائ عمان.

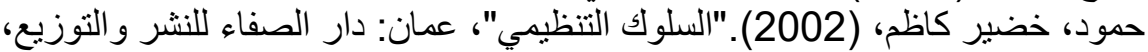


خليل،نبيل سعد.(2014)،إدارة المؤسسات التربوية في بداية الالفية الثالثة.ط(1) دار الفجر للنشر و التوزيع.القاهرة

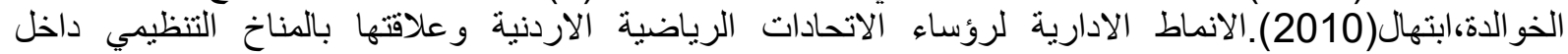

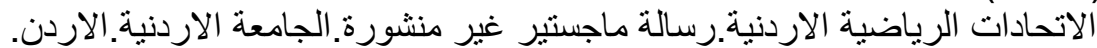

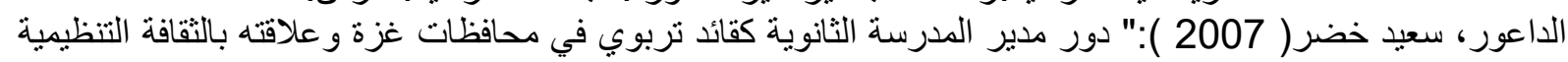

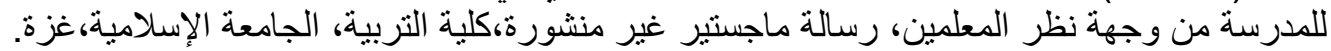

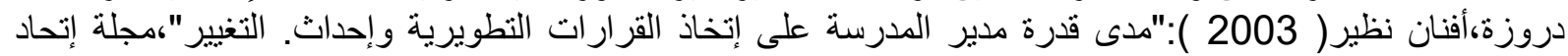

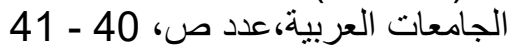

السعود، راتب وبطاح، أحمد. ( 1993 ). الختيار مدير المدرسة الثنانوية في الأردن - أسس مقترحة. أبحاث

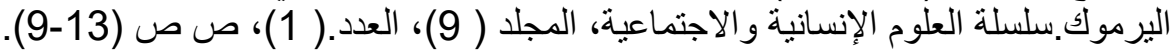

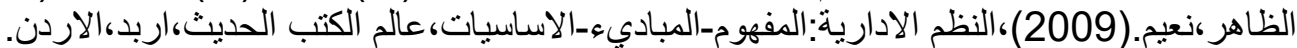

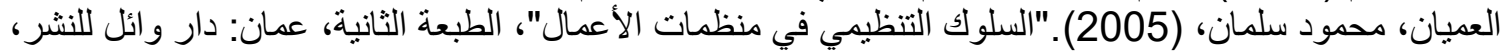

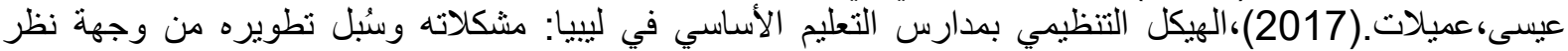

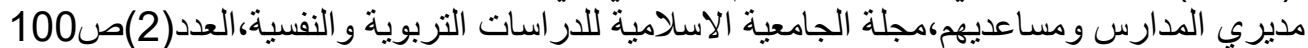

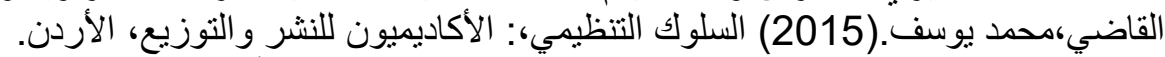

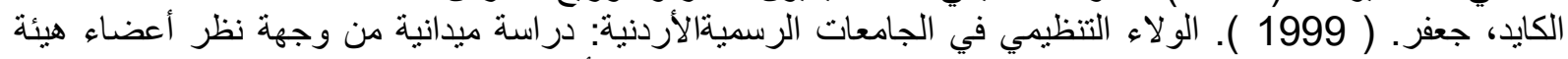

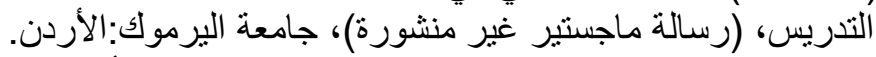

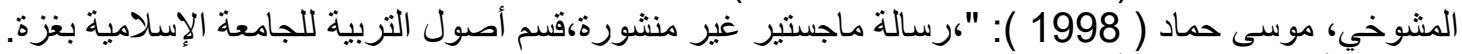

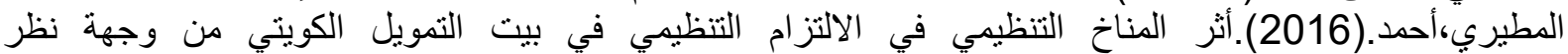

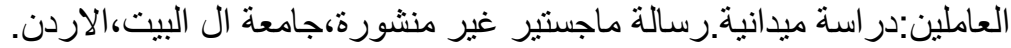

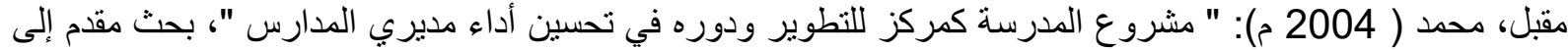

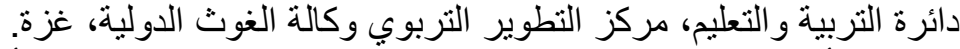

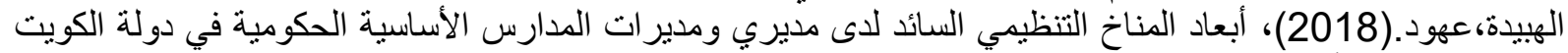

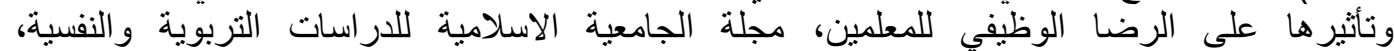

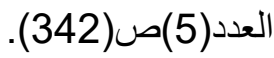

المراجع الأجنبية

Botha، R. J. (2013). The Need for Creative Leadership in South African Schools. African Studies، 72(2)، 307-320

Ifeoma، O. \& Eziuzor، G. (2015).Organizational climate types prevailing in public and private secondary schools in Delta North Senatorial Zone of Delta State Nigeria International Journal of Educational Policy Research and Review، 2(4): 47-51 